\title{
The Pecking Order of Segmentation and Liquidity-Injection Policies in a Model of Contagious Crises*
}

\author{
ALEXANDER GUEMBEL ${ }^{\dagger}$ and OREN SUSSMAN ${ }^{\ddagger}$
}

\author{
5th March 2019
}

\begin{abstract}
We study a two-country setting in which leveraged investors generate fire-sale externalities, leading to financial crises and contagion. Governments can affect the incidence of financial crisis and the degree of contagion by injecting public liquidity and, additionally, by segmenting the countries' liquidity markets. We show that segmentation allows a country to avoid contagion and fend off mild financial crises caused by a small shock to its liquidity demand, at the cost of exposing it to more severe financial crises caused by a large shock. We derive a "pecking order" result, whereby segmentation is a second-best measure that coordinated governments should use only when tax capacity constrains them from injecting liquidity. Even when segmentation is welfare-enhancing, it should be applied to public liquidity alone, never restricting the free flow of private liquidity across countries. Uncoordinated governments tend to use segmentation excessively.
\end{abstract}

JEL classification: G01, F32.

Keywords: Contagion, fire sales, financial crisis, financial stability, segmentation, liquidity injection.

\footnotetext{
*The paper was previously circulated under the title "A Welfare Analysis of Segmented Liquidity Markets". We would like to thank the editor (Dimitri Vayanos) and three anonymous referees for their careful reading and constructive comments. We also thank Bruno Biais, Elena Carletti, Vincent Fardeau, Jo Haubrich, Roman Inderst, Guillaume Plantin, Silvia Rossetto, Javier Suarez, and Jean Tirole as well as seminar and conference participants at Bangor Business School, Banque de France, Barcelona GSE Summer Forum, Bocconi, ESCP Paris, DIW (Berlin), Durham CEGAP, FIRS (Quebec City), EMF (Cardiff), the Luxembourg School of Finance, 7th International Moscow Finance Conference, Frankfurt School of Finance and Management, the Tinbergen Institute, Toulouse School of Economics, University of Leicester Business School, University of Porto, OxFIT, the Research Unit in Complexity and Economics conference, Paris, and SAET (Lisbon) for helpful comments and discussions. Guembel would like to thank the Institut Europlace de Finance and the Fédération Bancaire Française for financial support. All remaining errors are ours.

$\dagger$ Toulouse School of Economics, University of Toulouse Capitole (TSM)

$\ddagger$ University of Oxford, Saïd Business School
} 


\section{Introduction}

It has long been recognized that fire sales by a high-leverage financially-distressed investor, such as a bank or a hedge fund, localized in one market, may create a negative contagion effect for other investors localized in other markets: see, for example, Shleifer and Vishny (1992), Kiyotaki and Moore (1997), Lorenzoni (2008), Holmstrom and Tirole (2011) or Kuong (2015). ${ }^{1}$ The implication is that liquidity shocks may spread into connected markets, be amplified and trigger a financial crisis. It is therefore tempting to stipulate that segmenting the market to less connected, stand-alone units may contribute to financial stability and enhance social welfare. This argument is regarded as particularly relevant to the design of international financial architecture, and has recently gained support from policy-oriented authors, such as Haldane (2009), or Ostroy et. al. (2016). It is implied that although integrated financial markets bring about some benefits such as better diversification of risk, these benefits are of a second-order magnitude compared with the welfare cost of financial crisis.

Stiglitz (2010) summarizes this view succinctly: "with convex technologies and concave utility functions, risk sharing is always beneficial...But if technologies are not convex, then risk sharing can lower expected utility...While simplistic models typically employed in economics assume convexity, the world is rife with non-convexities."

To illustrate, Stiglitz (2010) introduces a simple example, which we slightly adapt as follows: there are two symmetric countries, $A$ and $B$, each facing a random liquidity shock, $\theta \in\left\{\theta^{h}, \theta^{l}\right\}$, high or low respectively, with independent realizations across the two countries. If the markets are integrated, both countries suffer a financial crisis once the combined shock exceeds a threshold $\theta^{*}$. If the markets are segmented, then each country suffers a crisis if its own shock exceeds $\frac{\theta^{*}}{2}$. Stiglitz considers the $\theta^{h}$ shock an extreme event so that

$$
\theta^{h}-\frac{\theta^{*}}{2}>\frac{\theta^{*}}{2}-\theta^{l}>0
$$

implying that $\theta^{h}+\theta^{l}>\theta^{*}$. It follows that an $h$ realization in one country is sufficient to push both into crisis: contagion. In contrast, once the markets are segmented each country suffers a financial crisis only if it draws the $\theta^{h}$ realization. ${ }^{2}$ It follows that the switch from segmentation to integration increases the probability of crisis. Assuming that

\footnotetext{
${ }^{1}$ The above literature focuses on contagion through fire sale externalities. Other sources of contagion may be direct credit exposure (Allen and Gale, 2000), wealth effects (Kyle and Xiong, 2001), or portfolio constraints (Pavlova and Rigobon, 2008). See also Davila and Korinek (2018) for a useful taxonomy of financial frictions that may generate financial amplification.

${ }^{2}$ Note that the same example can generate a diversification benefit from integration when $\theta^{h}+\theta^{l}<$ $\theta^{*}$. This is reminiscent of Acemoglu, Ozdaglar and Tahbaz-Salehi (2015), who show that the shock propagation properties of a network structure depend on the distribution of underlying shocks. They show that a network that allows effective diversification when negative shocks are small can turn into a fragile network when negative shocks are large.
} 
crisis is costly, integration decreases welfare, unambiguously.

The above example has obvious limitations. To see why, consider, first, the case where there is a third intermediate shock, $\theta^{m}$, above $\frac{\theta^{*}}{2}$ but small enough that $\theta^{l}+\theta^{m}<\theta^{*}$. Under segmentation, country $A$ is out of crisis whenever its own shock is mild $\left(\theta^{l}\right)$ and in crisis whenever its own shock is sufficiently severe (either $\theta^{m}$ or $\theta^{h}$ ). Under integration, $A$ suffers from contagion and slips into crisis when its own shock is mild, but $B^{\prime}$ s shock is high $\left(\theta^{l}, \theta^{h}\right)$. However, $A$ may now be rescued from crisis when its own shock is severe $\left(\theta^{m}\right)$ and $B^{\prime}$ s shock is mild $\left(\theta^{l}\right)$. Integration therefore reshuffles realizations across crisis events, lifting $A$ out of crisis some of the time when its shock is severe $\left(\theta^{m}\right)$, at the expense of exposing $A$ to contagion when its shock is mild $\left(\theta^{l}\right)$. The effect on the ex ante probability of crisis is ambiguous, but even if it stays the same, there is no reason to believe that such a reshuffling of crisis states is welfare neutral, except for the knife-edge case where the social cost of crisis is independent of the magnitude of the underlying shock. Second, if $\theta$ is interpreted as related to the demand for liquidity, then $\theta^{*}$ must be related to its supply. Liquidity may be supplied, privately, by profit-seeking speculators, or by welfare maximizing governments or, jointly, by both. Either way, $\theta^{*}$ should be endogenized, which would determine its position relative to various realizations and place the entire analysis on a more solid footing. Third, since governments inject liquidity and implement segmentation policies, welfare maximization should consider both policy instruments simultaneously. We show that accounting for the three points above has far reaching implications.

We construct a model with two countries, each having a population of risk-neutral investors, profit-seeking speculators who provide private liquidity and welfare maximizing governments that can inject liquidity, levy taxes and segment liquidity markets. Each investor has access to a single scalable project. Investors have only a limited endowment so that scaling up the project requires leverage. The use of debt contracts is fully endogenized. Investors are exposed to a "maintenance" shock, which we interpret as financial distress (see Holmstrom and Tirole, 1998). The fraction of distressed investors is $\theta$, itself a continuous random variable, constituting a macro shock that is independent across countries. Leverage implies that distressed investors are forced to fire-sell a fraction of their projects, thereby creating demand for liquidity. Applying "cash in the market" modelling (see Allen and Gale, 1994), the supply of liquidity, $L$, is endogenously determined by governments and speculators before the macro shock $\theta$ is realized. $L$ determines a threshold, $\theta^{*}$, such that a realization of $\theta$ in excess of $\theta^{*}$ results in a discontinuous drop of the fire-sale price, with contagion effects running within each country and, to the extent that markets are integrated, across countries. Governments choose their policies before speculators decide on their liquidity supply. That way, total liquidity supply and the probability of crisis are endogenized. Since investors' losses are not fully internalized by speculators, there is 
an under-provision of liquidity in a competitive equilibrium; liquidity is a public good. That situation may motivate governments to inject some extra liquidity and, at the same time, to consider segmentation policies to limit the incidence of cross-country contagion. The governments have no advantage of information, nor can they write contracts that private agents cannot write. The only reason why the governments can deploy effective policies is their ability to levy taxes (below, we argue that segmentation is akin to a tax), which allows them execute "unprofitable" trades and, thereby, internalize social values that private traders ignore.

The analysis reveals that segmentation has an inherent disadvantage. While the policy reduces the incidence of contagion, it also blocks liquidity outflows from a country with surplus liquidity that, in some circumstances, can prevent a crisis in the neighboring country that is experiencing a liquidity shortage. On the upside, by blocking contagion, segmentation can fend off a crisis, but only when the shock is mild so that domestic liquidity is sufficient to absorb all fire sales. On the downside, by blocking liquidity inflows from abroad, segmentation exposes a country to crisis when the domestic shock is severe (and the foreign shock is mild) so that domestic liquidity is insufficient to absorb all fire sales. It follows that segmentation tends to trade off a mild financial crisis for a severe one (see the reshuffling argument in the extended Stiglitz example, above). While this trade-off is generic, welfare accounting must weigh the equilibrium incidence of severe and mild shocks in crisis. As a result, there are cases where segmentation is welfare-enhancing. Our micro-founded model allows us to fully characterize these cases.

Three major insights emerge. First, it is never optimal to put any restrictions on the free flow of private liquidity. The reason is simple: the fundamental market failure in our model is that the competitive supply of liquidity is sub-optimal. The injection of public liquidity, subsidized by taxation, is always (locally) optimal at the competitive equilibrium. Segmentation operates similar to a tax that undermines the profitability and, thus, the supply of private liquidity. As a public good, liquidity should be subsidized, not taxed. Note that the injection of such subsidized public liquidity does crowd out private liquidity. Once the tax constraint is sufficiently relaxed, it is optimal to inject sufficient public liquidity to fully crowd out private liquidity. However, as long as speculators participate in the supply of private liquidity, it is never optimal to restrict their participation through segmentation.

The second result is akin to a "pecking order": coordinated governments (who maximize the joint welfare of the two countries) should inject liquidity first and segment only when tax capacity constrains them from injecting more liquidity. Supplying a public good - liquidity - should be the governments' preferred course of action as long as they have the tax capacity to do so. More accurately, we show that for any combination of structural parameters, there exists a sufficiently high level of tax capacity such that the segmentation 
of publicly injected liquidity is sub-optimal. A necessary condition for a welfare enhancing segmentation policy is that the tax constraint binds. In that case, segmentation can sometimes reduce the crisis probability and, thereby, increase welfare. Segmentation is an imperfect substitute to liquidity injection, a dominated course of action that should be used only when the preferred course of action is constrained.

The third insight is that there is (weakly) more segmentation in the Nash equilibrium where the governments fail to coordinate their policies ex ante. The reason is simple: absent coordination, each government internalizes the advantage of segmentation by avoiding liquidity outflows, but ignores the welfare loss it inflicts on its neighbour. Interestingly, this result is reminiscent of the old "beggar-thy-neighbour" effect as discussed, for example, by Stiglitz (1999).

Our assumptions with respect to the fire-sale market, the pivot of our theoretical analysis, are supported by a substantial body of empirical work. For example, Pulvino (1998) and Campbell et. al. (2011) document fire sale discounts in the airline and the real estate markets. Ellul et. al. (2011) follow Coval and Stafford (2007) in extending the results to financial assets. ${ }^{3}$ International finance applications tend to focus on emerging markets, c.f. Jotikasthira et. al. (2012) or Schnabl (2012), but recent events point towards wider relevance. For example, Mink and de Haan (2013) show that European banks experience abnormal returns around news events concerning Greece even when the banks had no direct exposure to Greek debt, consistent with the presence of contagion effects. $^{4}$

Veronesi and Zingales (2010) conduct a cost-benefit analysis of a liquidity injection of $\$ 125$ bn on October 13, 2008, by the US treasury to buy assets from ten distressed US banks. ${ }^{5}$ The cost to the US taxpayer - the expenditure ( $\$ 125$ bn) net of the value of the assets obtained in return - is between $\$ 21$ bn and $\$ 44$ bn. The benefits are estimated through the price impact that the policy had on the enterprise value of the banks, particularly their subordinated debt, totalling $\$ 130 \mathrm{bn}$. Since the benefits also accrue to US taxpayers, the policy was welfare-enhancing. It is worth noting that the above is an ex post welfare calculation (conditional on financial crisis), while we execute an ex ante welfare calculation, which also includes the opportunity cost of liquidity out of crisis and the governments' capacity to bear that cost. ${ }^{6}$

\footnotetext{
${ }^{3}$ See Duffie (2010) for a survey and a tentative explanation for why capital flows respond "slowly" to liquidity shortages.

${ }^{4}$ Based on simulation analysis, Mendoza and Quadrini (2010) argue that financial globalization significantly increased international spillovers due to the effect that asset price declines during crisis have on banks' balance sheets internationally.

${ }^{5}$ For other studies of public liquidity injections, see Krishnamurthy and Vissing-Jorgensen's (2015) analysis of large asset purchase programmes. Interactions between public and private liquidity are examined in Krishnamurthy and Vissing-Jorgensen, (2013).

${ }^{6}$ See Acharya et. al. (2014): sovereign default risk appears to increase following the bailout of private banks, indicating that capacity for bailout is indeed restricted.
} 
Our paper makes a contribution to the limits-of-arbitrage literature, in particular the part that deals with welfare and policy; see Gromb and Vayanos (2010) for a comprehensive survey. Gromb and Vayanos (2002) study an economy with dynamic risk-averse investors and arbitrage traders who are constrained by margin requirements. The authors find that "arbitrage activity benefits all investors ... [albeit] competitive arbitrageurs could ... fail to take a socially optimal level of risk". Gromb and Vayanos (2018) generalize the framework in several important dimensions and characterize the dynamics of arbitrage capital towards a steady state. Caballero and Simsek (2017) present a three-period model with a continuum of countries. Like us, they identify both the upside and downside of capital inflow. Our analysis shares with that literature the notion of segmentation. The main difference is that we treat segmentation as a policy instrument rather than a structural friction of the financial system. As such, we emphasize the crucial interrelations between segmentation and other policy tools, such as liquidity injections.

There is a developed, more applied, theoretical literature on the relationship between international capital flows and financial crisis: see Caballero and Krishnamurthy (2001, 2003, 2004), Gertler, Gilchrist and Natalucci (2007), Mendoza (2010) or Lorenzoni (2014) for an overview. Policy analysis in the form of Pigouvian taxes or capital controls are explored by Jeanne and Korinek (2010), Korinek (2010), Korinek (2011), or Brunnermeier and Sannikov (2015). ${ }^{7}$ In a banking context, Castiglionesi, Feriozzi, and Lorenzoni (2017) focus on the question of how integration affects liquidity supply and show that it may reduce banks' liquidity holdings. Brusco and Castiglionesi (2007) execute a welfare analysis of a two-country model with risk averse agents and Diamond-Dybvig (1983) banks. Macro shocks have a perfect, negative correlation so that the joint endowment is non-random. Direct diversification is possible, but is constrained by a moral hazard problem. Integration dominates segmentation, even when it fails to deliver the first best. The model is not designed to address the discontinuous nature of crisis, as highlighted by Stiglitz (2010) among others.

Another branch of the literature explores international policy coordination. ${ }^{8}$ Bengui (2014) studies a two-country model with risk-averse agents. Liquidity hoarding provides an imperfect substitute for state contingent contracts. Uncoordinated regulation may result in an equilibrium with under-provision of liquidity. Kara (2016) derives similar results in a setting where the insurance motive is shut down as the two country shocks are perfectly correlated. In our model, liquidity injection plays a similar role to liquidity regulation above, but the interaction between segmentation decisions and injection decisions

\footnotetext{
${ }^{7}$ Korinek (2016) provides an analysis of international spillovers and policy coordination in a very general framework. We differ in that we allow for amplification to introduce non-convexities into the production frontier.

${ }^{8}$ Policy coordination is also the subject of a literature on regulatory competition: see Acharya (2003), Dell'Ariccia and Marquez (2006), Morrison and White (2009).
} 
is shown to be critically important.

The remainder of the paper proceeds as follows. Section 2 sets out the model. Equilibrium and welfare in the single-country benchmark are analysed in Section 3. The two-country equilibrium is described in Section 4. Section 5 derives the joint segmentation/injection optimal policy when countries coordinate, and Section 6 studies the Nash equilibrium when countries choose policies without coordinating. Section 7 concludes. Throughout the paper, we refer to an online Appendix with several extensions.

\section{The setting}

There are four periods, $t=0,1,2,3$ and two countries, $i=A, B$. Each country has a measure-one continuum of investors, numerous speculators and a government that cares about the welfare of its own citizens. ${ }^{9}$ All agents are risk-neutral and discount future consumption using a unit factor. There is a storable consumption good, the numeraire of our model, which we label "cash" to facilitate economic interpretation. The net return from storing cash is zero in all periods. In period 0 , investors have a cash endowment, $w$. Speculators' cash endowments are sufficiently large so as not to impose binding constraints in equilibrium. The governments have no endowment.

Investors, speculators and governments can invest in an illiquid technology, such that 1 unit of cash invested in period 0 yields $\rho>1$ units of cash in period 3 . It is not possible to invest in the illiquid technology after period 0 , nor is it possible to convert it into cash before period 3. We take $\rho$ to be the opportunity cost of hoarding cash (supplying liquidity) in period 0 and denote by $L_{i}$ its amount in country $i$.

Each investor (but not speculators or governments) has access to a scalable "project". In period 0 , cash investment in the project is converted, one-to-one, into productive assets. This technology is irreversible: productive assets cannot be converted back to cash. Productive assets fully depreciate by the end of period 3. The scale of the project, measured in terms of productive assets, is denoted by $k$. If an investor wishes to operate at a scale exceeding his initial endowment, he will have to raise external funds, $b$, so that $k \leq w+b$.

In period 1, a measure $\theta_{i}$ of investors are affected by "financial distress" modelled as follows: A non-distressed investor generates cash flows $y_{2}$ and $y_{3}$ per unit of asset, in periods 2 and 3 , respectively. A distressed investor generates cash flows $y_{2}$ and $\gamma y_{3}$ per unit of asset, $0<\gamma<1$, unless he injects extra cash, $m>0$ per unit of asset, to "maintain" his project; see Holmstrom and Tirole (1998). The word "maintenance" should not be taken too literally; it can imply, for example, extra costs of operating the business or

\footnotetext{
${ }^{9}$ It is assumed that speculators reside and abide by the regulations of either country $A$ or $B$, an assumption that implies no loss of generality.
} 
higher than expected start-up costs. $\theta_{i}$, is a random variable, uniformly distributed on $[0, \Theta]$, with a zero correlation between $\theta_{A}$ and $\theta_{B}$.

In period 1 investors can "fire sell" a fraction $\lambda$ of their productive assets. The fire sale market is competitive and the fire sale price of a productive asset (in terms of cash) is denoted by $q$. We make the standard assumption that assets are less productive in the hands of a new owner due to, say, project specific human capital. ${ }^{10}$ Hence, the buyer's period 3 cash flow drops to $\delta y_{3}$ per unit of asset, $0<\delta<1$, if he bears the cost of maintenance, $m$, and $\gamma \delta y_{3}$ otherwise. We assume, for simplicity, that second period cash flows are not affected by an ownership change. Maintenance creates value:

$$
m<\delta(1-\gamma) y_{3}
$$

It is easy to see that if condition (2) holds, the original owner can generate even more (social) value by investing in maintenance.

The aggregate (predetermined) amount of cash available in period 1 is denoted by $L$. It comprises both private and public cash left over from period 0 after investments in projects and the illiquid technology have been made. We refer to $L$ as liquidity.

Projects are opaque to providers of external funds. Hence, they cannot contract on any project-specific contingency such as cash flows, maintenance work, scaling or descaling of the project. It is also impossible to tag specific units of assets. The no-tagging assumption excludes, by an arbitrage argument similar to Bhattacharya and Gale (1987), any scheme to purchase distressed productive assets at a price other than the market price, $q$. At the same time we do allow contracts contingent on the macro shock, $\theta_{i}$. In particular, we allow agents to issue securities contingent on $q$ (in equilibrium, a function of $\theta_{i}$ ), for example by writing put options on assets.

Providers of external finance can commit to punish default on contractual payment by project shut down. While the threat of "bankruptcy" can be effective in the enforcement of period 2 payments it cannot enforce period 3 payments, because at that point the assets' value is zero. Hence, all period 3 cash flows accrue to the investor as "rent" while period 2 cash flows can be pledged to the lender. Since equilibrium contracts include such penalty clauses (see below), we interpret external finance, $b$, as "debt". Notice that the combination of debt and a put option can be interpreted as debt indexation.

Under the above assumptions "investors" lend themselves to a banking interpretation. Banks' portfolios and cash flows are notoriously opaque. Due to "off the balance sheet" operations, even the scale of the portfolio is often unknown. The no-tagging assump-

\footnotetext{
${ }^{10}$ We assume, however, that governments are as effective as private buyers in operating assets bought on the fire sale market. When governments are less effective than private buyers at managing assets, the value of injecting public liquidity drops, with second-order implications on incentives to segment / integrate markets (see online Appendix).
} 
tion fits financial assets. Our bankruptcy penalties capture actions such as revoking an operating license or barring directors from future managerial positions.

Governments have two policy instruments. First, they can borrow cash from speculators in period 0 to be injected in period 1 into the fire sale market. Second, they can impose restrictions on cross-border liquidity outflows - segmentation policies. The policy mix of segmentation and injection is decided and announced simultaneously by the two countries in period 0 , before the realization of $\theta_{i}$ and before speculators and investors make their choices. ${ }^{11}$ Each government is committed to its announced policy. Since governments have no cash endowment to begin with, any liquidity that is set aside in period 0 must be funded by borrowing. Government debt is repaid through period-3 taxes, levied on the investors. ${ }^{12}$ To capture the convex nature of tax distortions, we assume that lump sum taxes can support borrowing up to an amount $G$ (same for both countries), but distortions prohibit any borrowing beyond that point.

As for segmentation policies, governments may prohibit the flow of liquidity out of the country. ${ }^{13}$ The policy is binary: the facility through which liquidity flows out is either open or shut. The policy applies to both private and public liquidity. When the facility is open, liquidity providers, private as well as public, are still allowed to set aside some liquidity for domestic use only.

We make four parametric assumptions.

$$
A 1: \quad \rho<\frac{y_{2}+\delta y_{3}}{y_{2}+\frac{m}{1-\gamma}}
$$

implies that the opportunity cost of liquidity, $\rho$, is sufficiently low to motivate speculators to provide it. Notice that inequality (2) is implied by $A 1$.

$$
A 2: \quad \rho>y_{2}+\delta y_{3}-m
$$

implies that the opportunity cost of funds is sufficiently high to guarantee finite project

\footnotetext{
${ }^{11}$ The assumption is motivated by the observation that restrictions on capital flows take a long time to implement. Empirical work by Fernandez et al. (2014) is consistent with the assumption: "we find that capital controls are remarkably acyclical". For analytical completeness, we study the ex post optimal allocation of liquidity in the online Appendix.

${ }^{12}$ That is, although investors' period 3 rents are not pledgeable (because lenders cannot verify their income at the individual level), they can be taxed by the government (at least as a group, say, by a tax on their anonymised purchase of consumption goods). Alternatively, we could assume that governments' operations are funded by a tax on speculators, in a manner that might affect the tax incidence but not the welfare analysis of our model (including the algebraic expressions below).

${ }^{13}$ In our model, governments have no reason to block inflows (unlike in some of the literature where capital controls can serve to curb excessive borrowing, e.g., Jeanne and Korinek, 2010, or Korinek, 2011). Consistent with our assumption, Fernandez et. al. (2015) find that most capital controls are on outflows rather than on inflows.
} 
size.

$$
A 3: \quad y_{2}+\delta y_{3}-m<\gamma y_{3}
$$

implies that even conditional on financial distress, the project can still generate sufficient rent to make repayment incentive compatible. Finally,

$$
A 4: \quad \rho \leq y_{2}+y_{3} \frac{1-\frac{\Theta}{2}(1-\gamma)}{1+\Theta\left[\frac{(1-\gamma) y_{3}}{m}-1\right]}
$$

guarantees that investors optimally borrow up to their debt capacity and hence fund a maintenance shock through fire sales. The parameter space as defined by assumptions $A 1$ to $A 4$ is non empty; see footnote 15 below.

\section{The single-country benchmark}

In this section we derive the single-country benchmark. For brevity, we omit the country index, $i$, throughout this section. Let $R$ be the constant debt repayment. We stipulate that under the optimal contract:

Conjecture 1. i) Debt repayment, $R$, is supported by a bankruptcy clause, is constant, and is determined by the lender's participation constraint:

$$
R=b \rho
$$

ii) All period 0 funds, both internal and external, are invested in the productive asset:

$$
k=b+w .
$$

iii) Projects are "leveraged up to the limit" defined by the available period 2 cash of non-distressed investors:

$$
R=y_{2} k
$$

Proposition 1 below demonstrates that this contract and the implied investors' policies are, indeed, optimal. Intuitively, investors fully repay their debt in order to avoid bankruptcy that would result in losing their period-3 rent (part $i$ ). Parametric assumption A3 implies that default is a dominated strategy: the investor could sell the project at date 1 at a maximum price $\left(y_{2}+\delta y_{3}-m\right) k$ and then default at date 2 , in which case he loses the payoff from carrying on with a damaged project, $\gamma y_{3} k .{ }^{14}$ Debt repayment is constant: the

\footnotetext{
${ }^{14}$ Note that $A 3$ also implies that the investor would not want to sell an intact project and then default.
} 
opacity assumption prevents the investors from writing contracts contingent of the event of their own project's distress. Moreover, if assets are exchanged in period 1, it must be at market prices as any other arrangement would open up an arbitrage opportunity (see also Bhattacharya and Gale, 1987). Our assumptions allow to index repayments on the observable macro shock, $\theta$, which would provide only an imperfect hedge against project distress, but are not used in equilibrium. The reason is related to part $i i$ ) of Conjecture 1: all of period 0 financial resources are invested in productive assets. It is not in the investor's best interest to hoard cash or buy securities that would generate cash in high- $\theta$ states, such as call options on assets. Doing so would provide some (imperfect) insurance against project distress, but that would come at the expense of decreasing project size and, thus, rents. See also Tirole (2006) for a discussion of the insurance-scale trade-off. Part $i$ ii) states that the scale of the project is constrained by period 2 pledgeable income which is all used for debt repayment.

Using (3)-(5) we solve for the project's scale:

$$
k=w \frac{\rho}{\rho-y_{2}},
$$

which is bounded by parametric assumption $A 2$.

Since, by part iii) of Conjecture 1, investors scale their projects up to their debt capacity, the only resource available to fund maintenance is the period-1 fire-sale of a certain fraction, $\lambda$, of productive assets. Since a downsized project generates less cash, and since it is still optimal to avoid bankruptcy, investors need to fire sell in period 1 in excess of the maintenance cost, and carry the remaining cash forward in order to pay period 2 debt. The combined periods 1 and 2 budget constraint is, thus: ${ }^{15}$

$$
\lambda q k+(1-\lambda) y_{2} k=(1-\lambda) m k+R
$$

We solve for $\lambda$ :

$$
\lambda(q)=\frac{m}{q+m-y_{2}} .
$$

Equation (8) already conveys the contagion effect: the lower is the fire sale price, $q$, the more assets the distressed investor needs to fire sell.

Ex post equilibrium prices are determined by the market clearing condition,

$$
L \geq \theta \eta(q+m) \lambda(q) k
$$

where $\eta$ is the fraction of distressed investors who fire-sell assets. Hence, in period 1, predetermined liquidity, $L$, should be sufficient to absorb fire sales by $\theta \eta$ investors, each

\footnotetext{
${ }^{15}$ To see that the difference $\lambda q k-(1-\lambda) m k$ is positive, use equations (5) and (6) to solve out $R$ as a function of $w$ and substitute in equation (8).
} 
selling a fraction $\lambda$ of $k$-sized projects. Each unit of asset takes $q$ units of cash to buy and, then, $m$ units of cash to maintain. A full characterization of the ex post (period 1) equilibrium is given as follows:

Proposition 1. For any amount of liquidity, L, there is a cut-off point, $\theta^{*}$, such that a period 1 realization, $\theta$, maps into events, $s \in\{n, c\}$, normal times and crisis times respectively, with fire-sale prices:

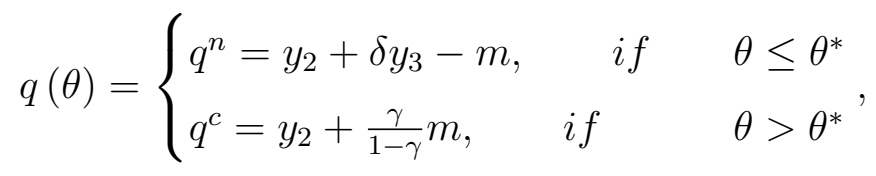

$q^{n}>q^{c}$ and

$$
\theta^{*}=\frac{L}{\left(q^{n}+m\right) \lambda^{n} k} .
$$

When $s=n$, the market clearing condition (9) holds with strict inequality, implying a slack in liquidity and $\eta=1$. When $s=c$, the market clearing condition (9) holds with equality and $\eta<1$; distressed investors are indifferent between carrying out and avoiding maintenance. Conjecture 1 describes the optimal (debt) contract, in equilibrium.

Proof. $q^{c}$ is determined by investors' indifference about maintenance: $\gamma y_{3} k=\left[1-\lambda\left(q^{c}\right)\right] y_{3} k$. Let $D(q, \theta) \equiv(q+m) \lambda(q) k \theta$, which is increasing in $\theta$ and decreasing in $q . q^{n}$ is determined by "fundamental" cash flows. Define $\theta^{*}$ such that $D\left(q^{n}, \theta^{*}\right)=L$. For any $\theta \leq \theta^{*}$, $D\left(q^{n}, \theta\right) \leq L$ (with strict inequality except for $\theta=\theta^{*}$ ), so that at $q^{n}$ the market-clearing condition (9) is satisfied with $\eta=1$. For any $\theta>\theta^{*}, D\left(q^{n}, \theta\right)>L$ so that there is insufficient liquidity to absorb all the fire sales at a price of $q^{n}$. Obviously, $D\left(q^{c}, \theta\right)>L$ so, at a price $q^{c}$ the market clearing condition (9) can only be satisfied with $\eta<1$. Notice that $\theta^{*}$ is the highest possible realization of $\theta$ for which a no-crisis equilibrium exists. To solve for $\theta^{*}$ substitute, $q=q^{n}$ and $\eta=1$ into the binding market clearing condition (9). For the optimality of the policy in Conjecture 1, see Appendix A.

Figure 1 illustrates. For $q>q^{c}$, the demand for liquidity is described by the graph of the $D$ function, as defined in the proof of Proposition 1, given a $\theta^{\prime \prime}$ realization. As mentioned above, the negative slope captures contagion: the lower the fire sale price is, the greater $\lambda$ is, the fraction of productive assets that distressed investors need to sell and, hence, the greater the demand for liquidity is. When the fire sale price drops to $q^{c}$, investors become indifferent between carrying out and avoiding maintenance. Hence, at that price the demand for liquidity "bends backwards" and becomes flat, as investors are willing to sell any amount in $\left[0, D\left(q^{c}, \theta^{\prime \prime}\right)\right]$. (There is no rationing in the conventional sense). As for the supply of liquidity, buyers of fire sale productive assets do not pay 
more than $q^{n}$, the "fundamental" price, and at period 1 cannot supply more liquidity than $L$. Hence, the supply curve is also decreasing in price, comprising a single step. It follows that given $\theta^{\prime \prime}$, the equilibrium price is $q^{c}$ and $\eta<1$. Generally, in crisis and across $\theta$ realizations, the number of distressed investors who obtain funding to maintain their projects is a fixed proportion, $\mu$, of $\theta^{*}$ :

$$
\theta \eta=\theta^{*} \mu, \quad \mu \equiv \frac{\lambda^{n}\left(q^{n}+m\right)}{\lambda^{c}\left(q^{c}+m\right)}<1,
$$

to be used below.

Given a lower magnitude shock, say $\theta^{\prime}$, graphed by the dashed line in Figure 1, the fire sale price is $q^{n}$ and the slack in liquidity at $q^{n}$ guarantees that all fire sales are absorbed at a price of $q^{n}$, so that all the distressed investors obtain funding to maintain their projects, $\eta=1$.

Between $\theta^{\prime}$ and $\theta^{\prime \prime}$, multiple equilibria may arise, in which case we select the (Pareto dominating) $q^{n}$ on grounds that the government can, at no cost, coordinate expectations to that price; see Kuong (2015) for a related point. Clearly, in between, there is a unique threshold, $\theta^{*}$, beyond which the only intersection is at the crisis price, $q^{c}$.

Similar to other models of its type, ours captures the dead weight loss of financial crisis: given a certain $\theta$, crisis implies a lower fire-sale price so that investors who maintain their projects need to liquidate a larger fraction in order to obtain the necessary funding. But then, the greater is $\theta$, the more distressed investors there are and the greater the intensity of the crisis is, which plays a pivotal role in our analysis. Moreover, our model captures an amplification effect of crisis, such that fire-sales prices drop discontinuously around a threshold level. This captures precisely the "non-convexity" in the production function that, according to Stiglitz (2010), turns the usual risk-sharing benefits of integration into a cost of contagion.

A buyer of an asset on the fire sale market earns, ex post, a gross rate of return of $r=\frac{y_{2}+\delta y_{3}}{q+m}$. It follows that speculators make no profit in normal times, $r^{n}=1$, but since

$$
r^{c}=\frac{y_{2}+\delta y_{3}}{y_{2}+\frac{m}{1-\gamma}}>1
$$

they do in crisis.

The $\theta^{*}$ threshold determines the probability of crisis, denoted by $\Psi\left(\theta^{*}\right)$, as follows:

$$
\Psi\left(\theta^{*}\right)=1-\frac{\theta^{*}}{\Theta}
$$


Figure 1: Ex post equilibrium

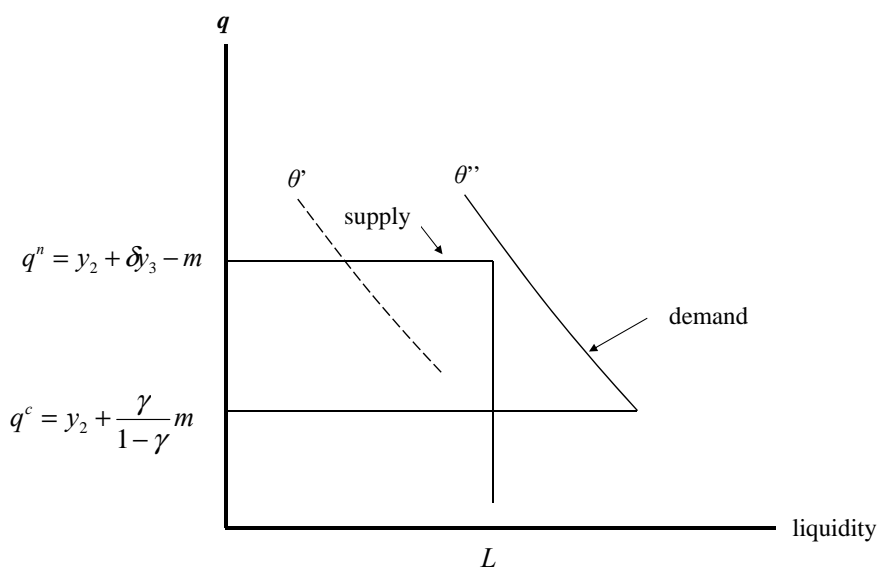

The ex ante expected gross rate of return on liquidity is, therefore:

$$
E(r)=\left[1-\Psi\left(\theta^{*}\right)\right] r^{n}+\Psi\left(\theta^{*}\right) r^{c} .
$$

Absent government intervention, liquidity is supplied by profit-driven speculators. Competition drives $E(r)$ down to the opportunity cost of liquidity, $\rho$, so that the speculators break even. The competitive probability of crisis is, therefore:

$$
\Psi^{e}=\frac{\rho-1}{r^{c}-1}
$$

Let $\theta^{e}$ be the corresponding crisis threshold, $\Psi\left(\theta^{e}\right)=\Psi^{e}$, and let $L^{e}$ be the competitive supply of liquidity, derived by applying $\theta^{e}$ to equation (11). Notice that a strictly positive probability of crisis is part of the normal functioning of such an economy; otherwise, the speculators have no incentive to supply any liquidity. See Allen and Gale (1998), Gorton and Huang (2004) or Acharya, Shin and Yorulmazer (2013) for a similar result.

Next, we turn to the analysis of the government's injection policy:

Proposition 2. Let $L_{G}$ be the government's injected liquidity. If $L_{G} \leq L^{e}$ the probability of crisis is $\Psi^{e}$ and private liquidity supply is $L^{e}-L_{G}$. If $L_{G}>L^{e}$ the probability of crisis is smaller than $\Psi^{e}$ and private liquidity supply is 0 .

Proof. Immediate using parametric assumption $A 1$.

Public liquidity injections below a level of $L^{e}$ are ineffective as they merely crowd out, one-for-one, private liquidity supply, with no effect on the total supply of liquidity. 
Above $L^{e}$, private liquidity supply is fully crowded out, because the government's injected liquidity drives the crisis probability below the speculator's break-even point.

Next, we derive the welfare function. Notice that regardless of the amount of liquidity that the government injects, the speculators earn the same rate of return on their wealth, $\rho$, including the case when they are fully crowded out. Moreover, since both the government's and the speculators' cost of liquidity is the same, $\rho$, welfare can be written as a function of total liquidity, regardless of the extent of speculators' participation.

The social welfare function can be derived in two ways: either by looking at a project's output or by looking at investors' income. Starting with the former, we can formulate total output as a function of the shock $\theta$, and the resulting state of the economy, $s \in\{n, c\}$. In the hands of a non-distressed investor, period-3 production per project is $p_{u}=y_{3} k$, regardless of $s$ (period 2 output is always fully used in order to compensate the lenders, so we can ignore it here). In the hands of a distressed investor, the $1-\lambda^{s}$ fraction that is maintained produces $\left(y_{3}-m\right) k$; the rest is transferred to second-best users who generate only $\left(\delta y_{3}-m\right) k$. Hence, the production of a project owned by an investor who invests in maintenance is $p_{d}^{s}=\left(1-\lambda^{s}\right)\left(y_{3}-m\right) k+\lambda^{s}\left(\delta y_{3}-m\right) k$. But then, in crisis $(s=c)$, only a fraction $\eta$ of distressed investors maintain their projects. The others produce just $\gamma y_{3} k$. Note that crisis entails an efficiency loss via an increase in $\lambda$ for all the distressed investors' projects. As we will see below, this also implies that the welfare loss due to a crisis is increasing in the number of distressed investors, $\theta \cdot{ }^{16}$ From output we need to subtract the opportunity cost of supplying liquidity $L$, which is $L(\rho-1)$.

We can now write

$$
\begin{aligned}
& W\left(\theta^{*}\right)=\int_{0}^{\theta^{*}}\left[(1-\theta) p_{u}+\theta p_{d}^{n}\right] \frac{d \theta}{\Theta} \\
& \quad+\int_{\theta^{*}}^{\Theta}\left[(1-\theta) p_{u}+\theta \eta p_{d}^{c}+\theta(1-\eta) \gamma y_{3} k\right] \frac{d \theta}{\Theta}-L(\rho-1) .
\end{aligned}
$$

Alternatively, investors' rent, $y_{u}=y_{3} k$, is the same whether the economy is in financial crisis or not. In contrast, distressed investors' rent, $y_{d}^{s}=\left(1-\lambda^{s}\right) y_{3} k, \lambda^{s} \equiv \lambda\left(q^{s}\right)$, is crisis related as $\lambda^{c}>\lambda^{n}$. But due to the indifference result in Proposition 1, in crisis, distressed investors' rent, $y_{d}^{c}$, is the same whether they maintain their projects or fail to do so and, as a result, is independent of $\eta$. Expected trading profits, net of the opportunity cost of supplying liquidity, are given by $\Psi\left(\theta^{*}\right)\left(r^{c}-1\right) L-(\rho-1) L$ and are lump-sum transferred

\footnotetext{
${ }^{16}$ This is an important deviation from the special case considered by Stiglitz (2010) whereby the cost of crisis is independent of the underlying shock. It is possible to provide a micro-foundation for that special case, for example, in a bank run model in which the shock triggers a run, but does not itself affect welfare conditional on a run occurring (see Allen and Gale, 1998).
} 
back to the investors. Hence, the welfare function is

$$
\begin{aligned}
& W\left(\theta^{*}\right)=\int_{0}^{\theta^{*}}\left[(1-\theta) y_{u}+\theta y_{d}^{n}\right] \frac{d \theta}{\Theta}+\int_{\theta^{*}}^{\Theta}\left[(1-\theta) y_{u}+\theta y_{d}^{c}\right] \frac{d \theta}{\Theta} \\
& +\Psi\left(\theta^{*}\right)\left(r^{c}-1\right) L-(\rho-1) L .
\end{aligned}
$$

The two derivations of welfare in equations (18) and (17) are equivalent, but are useful in producing different interpretations of the forces that operate in our model. Defining $Y \equiv \int_{0}^{\Theta}\left[(1-\theta) y_{u}+\theta y_{d}^{n}\right] \frac{d \theta}{\Theta}$ and using $\Psi^{e}$ from equation (16) we can rewrite welfare as

$$
W\left(\theta^{*}\right)=Y-\int_{\theta^{*}}^{\Theta} \theta \Delta \frac{d \theta}{\Theta}+\left[\Psi\left(\theta^{*}\right)-\Psi^{e}\right] \theta^{*} \Gamma,
$$

where

$$
\begin{aligned}
& \Delta \equiv p_{d}^{n}-\gamma y_{3} k=\left(\lambda^{c}-\lambda^{n}\right) y_{3} k=\frac{1}{\delta}\left[\delta(1-\gamma) y_{3}-m\right] k>0, \\
& \Gamma \equiv \mu\left(p_{d}^{c}-\gamma y_{3} k\right)=\lambda^{n}\left(q^{n}+m\right) k\left(r^{c}-1\right)=\mu\left[\delta(1-\gamma) y_{3}-m\right] k>0 .
\end{aligned}
$$

and $\mu$ is defined in equation (12), above; $\Delta$ and $\Gamma$ are expressed first in terms of project output, second in terms of rent, and third, directly in terms of model parameters.

Compute the derivative

$$
W^{\prime}\left(\theta^{*}\right)=\frac{\theta^{*}}{\Theta}(\Delta-\Gamma)+\Gamma\left[\Psi\left(\theta^{*}\right)-\Psi^{e}\right]
$$

Next, we define the government's liquidity-injection capacity,

$$
\theta_{G}^{*}=\frac{G}{\left(q^{n}+m\right) \lambda^{n} k}
$$

and state the basic welfare result of our analysis:

Proposition 3. Liquidity is under-supplied in a competitive equilibrium. Provided that it has the capacity to do so $\left(\frac{\theta_{G}^{*}}{\Theta}>1-\Psi^{e}\right)$, the government's optimal policy is to inject liquidity in excess of the competitive amount, $\theta^{*}>\theta^{e}$, which results in a full crowding out of private liquidity. If, in addition, $\Delta>2 \Gamma$ then optimal liquidity supply is given by the corner solution $\theta^{*}=\theta_{G}^{*}$. If the government cannot fully crowd out the competitive liquidity supply $\left(\frac{\theta_{G}^{*}}{\Theta} \leq 1-\Psi^{e}\right)$, it is (weakly) optimal for the government not to supply any liquidity.

Proof. $W^{\prime}\left(\theta^{e}\right)>0$ as $\Delta>\Gamma$ due to parametric assumption $A 1$. Using (14) it is clear that $W\left(\theta^{*}\right)$ is a convex function iff $\Delta>2 \Gamma$. The rest follows from the feasibility constraint (20) and Proposition 2. 
Competitive equilibrium, even in the single country case, is socially inefficient: $W^{\prime}\left(\theta^{e}\right)=$ $\frac{\theta^{*}}{\Theta}(\Delta-\Gamma)>0$. The root problem is project opacity. Had financial distress been observable, investors could write contingent insurance contracts that would funnel in the cash for maintenance work, making the fire-sale market redundant. That $W^{\prime}\left(\theta^{e}\right)>0$ implies an externality that makes liquidity a public good, under supplied in a competitive equilibrium. That externality is made of two parts: the " $\Delta$ effect" emerges because speculators fail to internalize that, by injecting extra liquidity, they can "lift" the threshold state, $\theta^{e}$, out of financial crisis, thereby decreasing the loss of rent for $\theta^{e}$ distressed investors from $\lambda^{c} y_{3} k$ to $\lambda^{n} y_{3} k$. The " $\Gamma$ effect" corrects for the fact that investors' valuation of the private cost of crisis is in excess of the social cost of crisis as they fail to internalize that the fire sale price, $q^{c}$, is lower than the "fundamental value" per unit of productive asset, $q^{n}$. That difference is captured by the speculators in the form of trading profits; it is easy to show that $L\left(r^{c}-1\right)=\eta \theta \lambda^{c}\left(q^{n}-q^{c}\right) k$. A project efficiency interpretation can be developed in parallel, emphasizing the efficiency losses generated when a shortage of funds prevents some investors from maintaining their projects.

The term $\frac{\theta^{*}}{\Theta}(\Delta-\Gamma)$ implies increasing returns to liquidity: the larger the amount of injected liquidity is, the larger the threshold, $\theta^{*}$, is, so that more distressed investors are affected, on the margin, by the injection of more liquidity. As we move away from the competitive equilibrium, $\Psi\left(\theta^{*}\right)$ no longer equals $\Psi^{e}$, and the extra term $\Gamma\left[\Psi\left(\theta^{*}\right)-\Psi^{e}\right]$ in equation (19) must be taken into consideration. This situation introduces decreasing returns to scale in liquidity because expected capital gains, $\Psi\left(\theta^{*}\right)\left(r^{c}-1\right) L$, are shaped as a Laffer curve, generating zero gains when either $L$ is zero, or when it is sufficiently high to drive the probability of crisis to zero. The net effect on the second derivative, $W^{\prime \prime}$, is therefore ambiguous and depends on the sign of $\Delta-2 \Gamma{ }^{17}$

\section{Two countries: ex post equilibrium}

Let $L_{i, D}, L_{i, T}$ and $L_{i, F}$ be country $i$ 's segmented (i.e., available for domestic use only), total and free-flowing liquidity, respectively: $L_{i, T} \equiv L_{i, D}+L_{i, F}$. Let $L \equiv L_{A, T}+L_{B, T}$ and $L_{F} \equiv L_{A, F}+L_{B, F}$ be the world's total and free-flowing liquidity, respectively. As in the single-country case, it is convenient to map these variables into the state space, dividing $L_{i, D}, L_{i, T}, L_{F}$, and $L$, by $\left(q^{n}+m\right) \lambda^{n} k$, to derive thresholds $\theta_{i, D}^{*}, \theta_{i, T}^{*}, \theta_{F}^{*}, \theta^{*}$ and $\theta_{G}^{*}$, respectively:

$$
\theta_{i, D}^{*}=\frac{L_{i, D}}{\left(q^{n}+m\right) \lambda^{n} k}
$$

\footnotetext{
${ }^{17}$ Parametric assumptions $A 1-A 4$ are consistent with $\Delta \gtrless 2 \Gamma$ as illustrated by the following numerical examples. For $y_{2}=0.25 ; y_{3}=2 ; \gamma=0.4 ; \delta=0.5 ; m=0.5 ; \Theta=0.6 ; \rho=1.05$, we have $\Delta>2 \Gamma$, while for $y_{2}=0.1 ; y_{3}=2 ; \gamma=0.4 ; \delta=0.6 ; m=0.55 ; \Theta=0.6 ; \rho=1.05$, we have $\Delta<2 \Gamma$.
} 
etc. In fact, four numbers are sufficient to describe the world's liquidity configuration; we find the vector $\boldsymbol{\theta}^{*}=\left(\theta_{A, D}^{*}, \theta_{B, D}^{*}, \theta_{A, T}^{*}, \theta^{*}\right)$ most convenient. We define the set of feasible liquidity configurations, $\mathcal{L}$ :

$$
\mathcal{L}=\left\{\boldsymbol{\theta}^{*} \mid 0 \leq \theta_{i, D}^{*} \leq \theta_{i, T}^{*}, \theta^{*} \leq 2 \Theta\right\}
$$

where $2 \Theta$ is the highest possible realization of the joint shock, $\theta_{A}+\theta_{B}$.

We can now characterize the ex post equilibrium: ${ }^{18}$

Proposition 4. Given a pre-determined liquidity configuration, $\boldsymbol{\theta}^{*}$, and a realization of shocks $\left(\theta_{A}, \theta_{B}\right)$, country $A$ can avoid a financial crisis (and sustain a fire-sale price of $q^{n}$ ) if:

i) $\theta_{A} \leq \theta_{A, D}^{*}$, (regardless of $\left.\theta_{B}\right)$;

or ii) $\theta_{A}>\theta_{A, D}^{*}$, and $\theta_{A} \leq \theta_{A, D}^{*}+\theta_{F}^{*}$ and $\theta_{A}+\theta_{B} \leq \theta_{A, D}^{*}+\theta_{B, D}^{*}+\theta_{F}^{*}$.

Otherwise, country $A$ suffers a financial crisis and the domestic fire sale prices drop to $q^{c}$. An analogous characterization applies to country $B$.

Proof. As in the proof of Proposition 1, we use $D(q, \theta) \equiv(q+m) \lambda(q) k \theta$. Then, country $A$ can avoid financial crisis if its own segmented liquidity is sufficient, $D\left(q^{n}, \theta_{A}\right) \leq L_{A, D}$, regardless of the situation in country $B$ (case $i$ ). When country $A$ 's liquidity is not sufficient, $D\left(q^{n}, \theta_{A}\right)>L_{A, D}$, country $A$ can still avoid financial crisis by drawing on free-flowing liquidity $D\left(q^{n}, \theta_{A}\right) \leq L_{A, D}+L_{F}$, provided that the world's total liquidity is sufficient to satisfy the joint demand of both countries $A$ and $B: D\left(q^{n}, \theta_{A}\right)+D\left(q^{n}, \theta_{B}\right) \leq$ $L_{A}+L_{B}+L_{F}($ case $i i)$.

Figure 2 illustrates. Realizations in cases $i$ ) are captured by rectangle $\theta_{A, D}^{*} \times \Theta$, while case $i$ i) expands the no crisis area to points below the downward sloping diagonal $\theta^{*}$ to $\theta^{*}$ up to $\theta_{A}=\theta_{A, D}^{*}+\theta_{F}^{*}$. Superimposing crisis realizations in both countries reveals four possible regimes: no crisis in either country, "systemic crisis" in both countries, and regional crisis in either country $A$ or $B$, denoted by areas $N C, S C, R C-A$ and $R C-B$, respectively.

A few technical steps are required before we proceed with our welfare analysis. When $\theta^{*}>\Theta$ the regional crisis area, $R C-B$, is empty for $\theta_{A, D}^{*}<\theta^{*}-\Theta$ because, for any realization $\theta_{A}<\theta^{*}-\Theta$, there is sufficient liquidity in the system to support country $B$ out of crisis even if $\theta_{B}$ is realized at its upper bound, $\Theta$. Any configuration with $\theta_{A, D}^{*}<\theta^{*}-\Theta$ is equivalent in all respects to the configuration $\theta_{A, D}^{*}=\theta^{*}-\Theta$. The same is obviously true for $\theta_{B, D}^{*}$. Hence, we can restrict attention to the "relevant area", defined as $\mathcal{L}^{R} \subseteq \mathcal{L}$ :

$$
\mathcal{L}^{R} \equiv\left\{\boldsymbol{\theta}^{*} \in \mathcal{L} \mid \theta_{i, D}^{*} \geq \theta^{*}-\Theta\right\}
$$

\footnotetext{
${ }^{18}$ Note that the optimal financial contract remains unchanged because contractual insurance opportunities are not improved in the two-country case.
} 
Figure 2: Equilibrium regimes

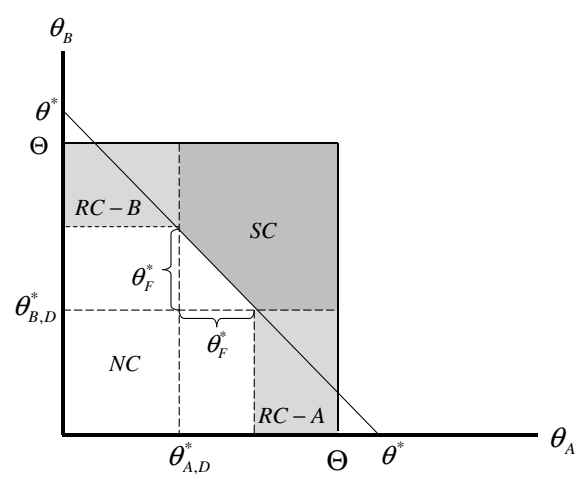

For realizations $\theta_{A} \in\left(\theta_{A, D}^{*}, \theta_{A, D}^{*}+\theta_{F}^{*}\right]$, whether country $A$ ends up in financial crisis depends on country- $B$ 's realization, $\theta_{B}$, which already indicates the presence of crosscountry contagion. Hence, define country- $A$ 's probability of financial crisis, conditional on the realization of its own shock, $\theta_{A}$, and given a liquidity configuration within the relevant area, $\boldsymbol{\theta}^{*} \in \mathcal{L}^{R}$, by the function $\psi_{A}\left(\theta_{A} ; \boldsymbol{\theta}^{*}\right)$, as follows:

$$
\psi_{A}\left(\theta_{A}, \boldsymbol{\theta}^{*}\right) \equiv \operatorname{Pr}\left(q_{A}=q^{c} \mid \theta_{A}\right)=\left\{\begin{array}{lll}
0 & \text { for } & \theta_{A} \in\left[0, \theta_{A, D}^{*}\right], \\
1-\frac{\theta^{*}-\theta_{A}}{\Theta} & \text { for } & \theta_{A} \in\left(\theta_{A, D}^{*}, \theta^{*}-\theta_{B, D}^{*}\right] . \\
1 & \text { for } & \theta_{A} \in\left(\theta^{*}-\theta_{B, D}^{*}, \Theta\right]
\end{array}\right.
$$

An analogous ${ }^{19}$ definition applies to country $B$. Figure 2 illustrates: for a $\theta_{A} \in\left(\theta_{A, D}^{*}, \theta_{A, D}^{*}+\theta_{F}^{*}\right]$, the values of $\psi_{A}$ are represented by the length of the vertical line between $\Theta$ and the $\theta^{*}$ to- $\theta^{*}$ diagonal, at $\theta_{A}$, divided by $\Theta$.

We can now derive the ex ante probability of a crisis in country $i$ for any liquidity configuration $\boldsymbol{\theta}^{*} \in \mathcal{L}^{R}$,

$$
\Psi_{i}\left(\boldsymbol{\theta}^{*}\right) \equiv \operatorname{Pr}\left(q_{i}=q^{c}\right)=\int_{0}^{\Theta} \psi_{i}\left(\theta_{i}\right) \frac{d \theta_{i}}{\Theta},
$$

and the probability of crisis in either of the two countries,

\footnotetext{
${ }^{19}$ With the slight asymmetry that in $\psi_{A}\left(\theta_{A} ; \boldsymbol{\theta}^{*}\right)$ the first (second) element in $\boldsymbol{\theta}^{*}$ denotes the country's own (neighbour) segmented liquidity and in $\psi_{B}\left(\theta_{B} ; \boldsymbol{\theta}^{*}\right)$ the order is reversed.
} 


$$
\begin{aligned}
\Psi_{A \vee B}\left(\boldsymbol{\theta}^{*}\right) & \equiv \operatorname{Pr}\left(q_{A}=q^{c} \vee q_{B}=q^{c}\right)=\Psi_{A}\left(\boldsymbol{\theta}^{*}\right)+\int_{\theta_{B, D}^{*}+\theta_{F}^{*}}^{\Theta} \psi_{B}\left(\theta_{B} ; \boldsymbol{\theta}^{*}\right) \frac{d \theta_{B}}{\Theta} \\
& =1-\frac{1}{2}\left[\left(\frac{\theta^{*}}{\Theta}\right)^{2}-\left(\frac{\theta_{A, D}^{*}}{\Theta}\right)^{2}-\left(\frac{\theta_{B, D}^{*}}{\Theta}\right)^{2}\right]
\end{aligned}
$$

Notice that since $\psi_{A}$ is defined over the relevant area, the functions that are derived from it are also defined over the relevant area. Due to its important role, we state the following straightforward result:

Corollary 1. $\Psi_{A \vee B}\left(\boldsymbol{\theta}^{*}\right)>\Psi_{i}\left(\boldsymbol{\theta}^{*}\right)$ : the probability of crisis in country $A$, for example, is strictly smaller than the probability of crisis in either country $A$ or in country $B$, unless the regional crisis areas, $R C-A$ and $R C-B$ are both empty.

To execute the welfare analysis of Sections 5 and 6 , we derive the ex ante welfare function of country $A$ :

$$
\begin{aligned}
W_{A}\left(\boldsymbol{\theta}^{*}\right) & =Y-\int_{0}^{\Theta} \psi_{A}\left(\theta_{A} ; \boldsymbol{\theta}^{*}\right) \theta_{A} \Delta \frac{d \theta_{A}}{\Theta} \\
& +\Gamma\left[\theta_{A, D}^{*} \Psi_{A}\left(\boldsymbol{\theta}^{*}\right)+\left(\theta_{A, T}^{*}-\theta_{A, D}^{*}\right) \Psi_{A \vee B}\left(\boldsymbol{\theta}^{*}\right)\right] \\
& -L_{A, T}(\rho-1)
\end{aligned}
$$

For reasons already articulated in the derivation of the single-country welfare function (18), the notation need not distinguish between private and public liquidity, nor is it necessary to include the speculators in the welfare calculus. That being said, there are circumstances in which segmented or free-flowing liquidity can be supplied only privately or only publicly. The analysis of these cases makes the identity of the supplier perfectly clear, without further burdening the notation; see below. When analyzing the joint welfare optimum we focus on country $A$ welfare as a function of a symmetric change in policies in countries $A$ and $B$. Since countries are symmetric, this is the same as analyzing the effect of the policy in $A$ on the sum of welfare in $A$ and $B$.

The top line in equation (26) captures the $\Delta$ effect, that is, the loss of rent or productivity across different realizations of $\theta_{A}$ due to financial crisis, relative to a base level, $Y$. The second line captures the $\Gamma$ effect, that is the lump sum transfer of the government's capital gains back to the investor population or, alternatively, the enhanced efficiency for the $\eta$ fraction of projects which are maintained. The third line captures the opportunity cost of liquidity. 


\section{Two countries: welfare analysis with coordinated governments}

Figure 2 already provides the basic intuition that drives our analysis. Consider a policy that replaces a fully integrated market, where all liquidity can flow freely between two countries, with a partially segmented market where the amounts $\left(\theta_{A, D}^{*}, \theta_{B, D}^{*}\right)$ are restricted for domestic use only; total liquidity, $\theta^{*}$, is fixed across the policy switch. Clearly, such segmentation ex post benefits country $A$ in some circumstances: when it is affected by a shock that is sufficiently mild so that it can be accommodated by domestic segmented liquidity, $\theta_{A}<\theta_{A, D}^{*}$, yet country $B$ is hit by a severe shock that could spread out via contagion and drag both countries into crisis had the markets been integrated, $\theta_{A}+\theta_{B}>$ $\theta^{*}$. (The argument applies to points above the $\theta^{*}$-to- $\theta^{*}$ diagonal and to the left of the $\theta_{A, D}^{*}$ vertical.) In sharp deviation from standard neo-classical models, the equalization of asset prices across countries is no longer a necessary condition for economic efficiency. In an online Appendix we provide a comprehensive analysis of the ex post state contingent segmentation policies. ${ }^{20}$

An ex ante welfare analysis must account for the fact that a policy of segmentation can undermine country $A$ 's welfare in other circumstances: when it is affected by a severe shock that cannot be deflected using segmented and free-flowing liquidity, $\theta_{A}>\theta_{A, D}^{*}+\theta_{F}^{*}$, yet country $B$ is hit by a shock mild enough so that had the two countries been integrated, the total liquidity would suffice to rescue both from crisis, $\theta_{A, D}^{*}+\theta_{B, D}^{*}<\theta^{*}$. (The argument applies to points below the $\theta^{*}$-to- $\theta^{*}$ diagonal and to the right of left of the $\theta_{A, D}^{*}+\theta_{F}^{*}$ vertical.) Crucially, the upside of segmentation affects only small $\theta_{A}$ realizations, while the downside affects large $\theta_{A}$ realizations. Hence, segmentation "buys" country $A$ relief from a mild crisis at the cost of exposing it to a severe crisis.

The argument above is made from the point of view of country $A$, under the assumption of symmetric reciprocity by country $B$. In particular, country $A$ can collect the benefits from integration only to the extent that country $B$ removes the restrictions on the outflow of $\theta_{B, D}^{*}$ in return for country $A$ lifting the restrictions on the outflows of $\theta_{A, D}^{*}$. Such reciprocity assumes coordination. The result is equivalent to a "central planner" who maximizes the joint welfare of both countries with respect to $\theta_{A, D}^{*}=\theta_{B, D}^{*}$, and, in the comprehensive version of the analysis, below, $\theta^{*}$ as well. That is, we evaluate the net benefit of segmentation in terms of avoiding contagion in some states and increasing

\footnotetext{
${ }^{20}$ That is, we relax the assumption that segmentation policies take a long time to implement and, hence, must be decided before the realization of $\left[\theta_{A}, \theta_{B}\right]$. Interestingly, the optimal policy has a triagelike property in that liquidity is segmented towards the country hit by the most severe shock, provided that the country can be rescued; otherwise, segmented liquidity should be directed towards the lesser affected country. Again, the assumption that the social cost of crisis is increasing in the magnitude of the shock plays a pivotal role in the argument.
} 
exposure to crisis in others, as well as the net benefit of reducing the overall incidence of crisis through public liquidity injections. As in the single-country case, governments' ability to inject liquidity depends on their tax capacity. We proceed with the analysis by distinguishing three cases: $i$ ) when the governments have no capacity to inject any liquidity $(G=0)$; $i i)$ when the governments' capacity is sufficiently high to fully crowd out all private liquidity; and $i$ ii) when the governments have an intermediate capacity so that they can only crowd out some, but not all private liquidity. Section 5.4 brings together the results from the three cases.

\subsection{Zero tax capacity, $\frac{\theta_{G}^{*}}{\Theta}=0$}

Having no liquidity injection capacity, the only policy decision that the governments have in the $G=0$ case is whether to leave the facility through which private liquidity can flow out of the country open or closed. Consider the case where both countries coordinate a policy of segmentation. Clearly, this case reduces to that of two isolated countries, each with a supply of private, segmented liquidity of $\theta^{e}$ and an ex ante probability of financial crisis $\Psi^{e}$ as derived in Section 3. Denote by $\boldsymbol{\theta}_{S}^{*}$ the corresponding liquidity configuration, that is, $\left(\theta_{A, D}^{*}, \theta_{B, D}^{*}, \theta_{A, T}^{*}, \theta^{*}\right)=\left(\theta^{e}, \theta^{e}, \theta^{e}, 2 \theta^{e}\right)$. Alternatively, consider the case where both governments allow a free flow of liquidity. Speculators provide liquidity up to the break-even point so that the liquidity configuration is $\boldsymbol{\theta}_{F}^{*}=\left(0,0, \theta_{A, T}^{*}, \theta_{F}^{*}\right)$, such that $\Psi_{A \vee B}\left(\boldsymbol{\theta}_{F}^{*}\right)=\Psi^{e}$. Note that $\theta_{A, T}^{*}$ is immaterial to the determination of $\theta_{F}^{*}$, which is uniquely determined regardless of the allocation of free-flowing liquidity between the speculators of country $A$ and those of country $B$.

It follows that country $A$ 's (and $B$ 's) probability of financial crisis is not affected by the governments' segmentation policies: $\Psi_{A}\left(\boldsymbol{\theta}_{S}^{*}\right)=\Psi_{A}\left(\boldsymbol{\theta}_{F}^{*}\right)=\Psi^{e}$. Hence, although the policy does redistribute $\left(\theta_{A}, \theta_{B}\right)$ realizations across crisis and no-crisis events, on the balance of probabilities (but not welfare!) segmentation is neutral: the measure of realizations that the policy switch rescues from crisis must be equal to the measure of realizations that it draws into crisis. Equation (27), which plays an important role in the proof of Proposition 5 below, provides a formal statement; we express the equality $\Psi_{A}\left(\boldsymbol{\theta}_{F}^{*}\right)=\Psi_{A}\left(\boldsymbol{\theta}_{S}^{*}\right)$ in terms of integrals over $\psi_{A}\left(\theta_{A} ; \boldsymbol{\theta}_{F}^{*}\right)$ and $\psi_{A}\left(\theta_{A} ; \boldsymbol{\theta}_{S}^{*}\right)$, which we split at the point $\theta_{A}=\theta^{e}$ and then rearrange:

$$
\int_{0}^{\theta^{e}}\left[\psi_{A}\left(\theta_{A} ; \boldsymbol{\theta}_{F}^{*}\right)-\psi_{A}\left(\theta_{A} ; \boldsymbol{\theta}_{S}^{*}\right)\right] \frac{d \theta_{A}}{\Theta}=\int_{\theta^{e}}^{\Theta}\left[\psi_{A}\left(\theta_{A} ; \boldsymbol{\theta}_{S}^{*}\right)-\psi_{A}\left(\theta_{A} ; \boldsymbol{\theta}_{F}^{*}\right)\right] \frac{d \theta_{A}}{\Theta} \text {. }
$$

Since $\psi_{A}\left(\theta_{A} ; \boldsymbol{\theta}_{S}^{*}\right)$ equals zero (one) to the left (right) of $\theta^{e}$, the RHS (LHS) of the equation captures the upside (downside) of segmentation in terms of decreased (increased) crisis probability. The two sides of the equation correspond to the two equal-area shaded 
Figure 3: Two countries, $G=0$, free flow versus segmentation, $\Psi^{e}>\frac{1}{2}$

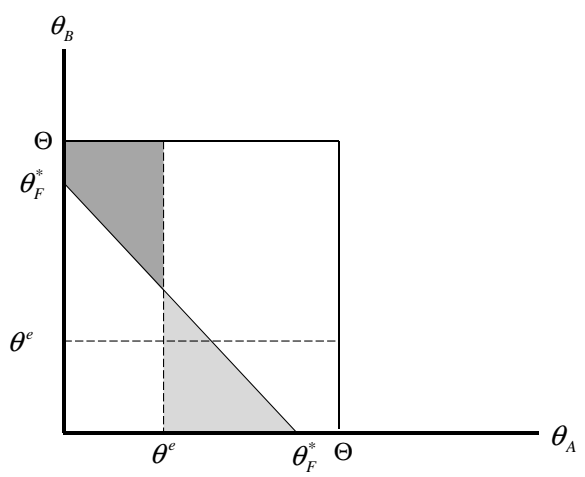

polygons in Figure $3 .^{21}$

Proposition 5. When governments have no tax capacity $(G=0)$ so that all liquidity is supplied competitively by speculators, it is optimal for the governments of countries $A$ and $B$ to coordinate a policy that allows private liquidity to flow freely.

Proof. Note that under either configuration $\boldsymbol{\theta}_{F}^{*}$ or $\boldsymbol{\theta}_{S}^{*}$ the expected return on liquidity is just $\rho$ so that the second and third lines of the welfare function (26) cancel each other. Splitting the integration of $W_{A}$ at $\theta^{e}$,

$$
W_{A}\left(\boldsymbol{\theta}_{F}^{*}\right)=Y-\int_{0}^{\theta^{e}} \psi_{A}\left(\theta_{A} ; \boldsymbol{\theta}_{F}^{*}\right) \theta_{A} \Delta \frac{d \theta_{A}}{\Theta}-\int_{\theta^{e}}^{\Theta} \psi_{A}\left(\theta_{A} ; \boldsymbol{\theta}_{F}^{*}\right) \theta_{A} \Delta \frac{d \theta_{A}}{\Theta}
$$

using the fact that $\psi_{A}$ equals to zero (one) to the left (right) of $\theta^{e}$,

$$
\begin{aligned}
W_{A}\left(\boldsymbol{\theta}_{F}^{*}\right) & =Y-\int_{0}^{\theta^{e}}\left[\psi_{A}\left(\theta_{A} ; \boldsymbol{\theta}_{F}^{*}\right)-\psi_{A}\left(\theta_{A} ; \boldsymbol{\theta}_{S}^{*}\right)\right] \theta_{A} \Delta \frac{d \theta_{A}}{\Theta} \\
& -\int_{\theta^{e}}^{\Theta}\left[\psi_{A}\left(\theta_{A} ; \boldsymbol{\theta}_{F}^{*}\right)+1-\psi_{A}\left(\theta_{A} ; \boldsymbol{\theta}_{S}^{*}\right)\right] \theta_{A} \Delta \frac{d \theta_{A}}{\Theta}
\end{aligned}
$$

and the fact that $\theta^{e}$ is an upper (lower) bound on $\theta_{A}$ to the left (right) of $\theta^{e}$ yields

\footnotetext{
${ }^{21}$ Point $\left(\theta^{e}, \theta^{e}\right)$ lies below (above) the diagonal when $\theta_{F}^{*}$ is smaller (greater) than $\Theta$.
} 


$$
\begin{aligned}
W_{A}\left(\boldsymbol{\theta}_{F}^{*}\right)> & Y-\theta^{e} \Delta\left\{\int_{0}^{\theta^{e}}\left[\psi_{A}\left(\theta_{A} ; \boldsymbol{\theta}_{F}^{*}\right)-\psi_{A}\left(\theta_{A} ; \boldsymbol{\theta}_{S}^{*}\right)\right] \frac{d \theta_{A}}{\Theta}-\int_{\theta^{e}}^{\Theta}\left[\psi_{A}\left(\theta_{A} ; \boldsymbol{\theta}_{S}^{*}\right)-\psi_{A}\left(\theta_{A} ; \boldsymbol{\theta}_{F}^{*}\right)\right] \frac{d \theta_{A}}{\Theta}\right\} \\
& -\int_{\theta^{e}}^{\Theta} \theta_{A} \Delta \frac{d \theta_{A}}{\Theta} .
\end{aligned}
$$

Using (27), we conclude

$$
W_{A}\left(\boldsymbol{\theta}_{F}^{*}\right)>Y-\int_{\theta^{e}}^{\Theta} \theta_{A} \Delta \frac{d \theta_{A}}{\Theta}=W_{A}\left(\boldsymbol{\theta}_{S}^{*}\right)
$$

An analogous argument applies to country $B$.

The intuition is straightforward. A policy of segmentation is neutral in terms of probabilities. Nevertheless, segmentation is dominated in terms of welfare. Although it prevents crises by avoiding contagion, this is only possible for relatively mild shocks, as country $A$ has only its own liquidity to fend off a crisis. On the other hand, segmentation exposes country $A$ to crises by denying it access to its neighbour's liquidity. In other words, precisely when a shock is too intense to be handled by the country's own liquidity, segmentation denies it the chance of being rescued by drawing on its neighbours liquidity. Hence, segmentation trades off severe financial crises for equal-probability mild financial crises. This trade-off is pivotal in the welfare analysis below, even for the cases where $G$ no longer equals zero.

Although Proposition 5 is derived under the specific assumptions of our model, we believe that the argument is more general. For example, we assume, for tractability, that cash flows, $y_{2}, \gamma y_{3}$, and $\delta y_{3}$ as well as the maintenance cost $m$ are independent of $\theta$. This assumption renders fire sale prices $\left\{q^{n}, q^{c}\right\}$ invariant across realizations within the $\{n, c\}$ events. In general, cash flows, prices and ex post rates of return on liquidity could vary with the shock. As a result, the speculators' break even condition (16) may have a more complicated structure so that the policies are no longer probability neutral. Nevertheless, our basic trade-off is likely to survive as long as the social cost of crisis is increasing in the magnitude of the shock. That is, segmentation blocks contagion but leaves countries to their own devices; hence, it contributes to welfare when the shock is small. At the same time, segmentation also blocks liquidity inflows; it therefore undermines welfare when the shock is too large to be accommodated by domestic resources alone.

Another general point worth making is that free flow of liquidity may welfare dominate segmentation despite the fact that it brings about perfect correlation in crisis incidence across countries. There is a tendency to assign welfare values to empirical findings that document increased correlation under integration, particularly in times of crisis; c.f. Londono (2016), Das and Uppal (2004) or Longin and Solnik, (2001). By itself, crisis 
correlation has no welfare implication. Our analysis suggests greater caution in drawing welfare interpretations from plain correlations.

\subsection{Full crowding out $\left(\frac{\theta_{G}^{*}}{\Theta} \geq \sqrt{1-\Psi^{e}}\right)$}

Consider, next, the other extreme case where the governments have a sufficiently high tax capacity, $G$, so that they can crowd out the entire supply of private liquidity. Notably, even when the governments keep the facility through which liquidity flows across countries open, they can still decide to segment the market by allocating some of their liquidity for domestic use only, a decision which they will make, announce and commit to, ex ante. In this case, Corollary 1 still holds: segmented liquidity bears a lower rate of return than free-flowing liquidity, but the governments, which are not motivated by profit, can ignore the "arbitrage opportunity" if it serves their welfare objectives. Hence, unlike in the $G=0$ case, we can no longer restrict the analysis to the corners of full or zero segmentation. Technically, each government makes a policy decision with respect to two continuous variables: the total amount of liquidity that they inject, $\theta_{i, T}^{*}$, out of which they segment the amount $\theta_{i, D}^{*}$ for domestic use only. The rest, $\theta_{i, T}^{*}-\theta_{i, D}^{*}$, can flow freely.

To execute the analysis, we compute the partial derivatives of $W_{A}$ using (24), (25) and (26):

$$
\begin{gathered}
\frac{\partial W_{A}\left(\boldsymbol{\theta}^{*}\right)}{\partial \theta_{A, D}^{*}}=\Gamma \frac{\theta_{A, D}^{*}}{\Theta}\left[\left(1-\frac{\theta^{*}-\theta_{A, D}^{*}}{\Theta}\right)\left(\frac{\Delta}{\Gamma}-2\right)+\frac{\left(\theta_{A, T}^{*}-\theta_{A, D}^{*}\right)}{\Theta}\right], \\
\frac{\partial W_{A}\left(\boldsymbol{\theta}^{*}\right)}{\partial \theta_{A, T}^{*}}=\Gamma\left(\Psi_{A \vee B}-\Psi^{e}\right), \\
\frac{\partial W_{A}\left(\boldsymbol{\theta}^{*}\right)}{\partial \theta_{B, D}^{*}}=-\Gamma \frac{\theta_{B, D}^{*}}{\Theta}\left[\frac{\Delta}{\Gamma} \frac{\theta^{*}-\theta_{B, D}^{*}}{\Theta}-\frac{\theta_{A, T}^{*}}{\Theta}\right], \\
\frac{\partial W_{A}\left(\boldsymbol{\theta}^{*}\right)}{\partial \theta^{*}}=\Delta\left(1-\Psi_{A \vee B}\right)+\Gamma\left[\left(\frac{\theta_{A, D}^{*}}{\Theta}\right)^{2}-\left(\frac{\theta_{A, T}^{*}}{\Theta}\right)\left(\frac{\theta^{*}}{\Theta}\right)\right] .
\end{gathered}
$$

For the rest of this section we focus on the symmetric case, whereby $\theta_{T}^{*} \equiv \theta_{A, T}^{*}=\theta_{B, T}^{*}$ and $\theta_{D}^{*} \equiv \theta_{A, D}^{*}=\theta_{B, D}^{*}$ denote the country level symmetric total and segmented liquidity, respectively, so that the generic liquidity configuration in this case is $\boldsymbol{\theta}_{M}^{*}=\left(\theta_{D}^{*}, \theta_{D}^{*}, \theta_{T}^{*}, 2 \theta_{T}^{*}\right)$. To find the critical tax capacity that allows the governments to drive the crisis probability below its competitive level (if they wish to do so) we substitute equation (25) into $\Psi_{A \vee B}\left(\theta_{G}^{*}, \theta_{G}^{*}, \theta_{G}^{*}, 2 \theta_{G}^{*}\right) \leq \Psi^{e}$ and solve out $\frac{\theta_{G}^{*}}{\Theta} \geq \sqrt{1-\Psi^{e}} \cdot{ }^{22}$ Section 5.3 completes the analysis by focusing on the parameter region where $\frac{\theta_{G}^{*}}{\Theta}<\sqrt{1-\Psi^{e}}$.

\footnotetext{
${ }^{22}$ Note that full crowding out requires a higher tax capacity than in the single-country case. This is because public liquidity is segmented, while private liquidity is free to flow across two countries. For a given level of public liquidity, private liquidity therefore earns a higher rate of return than in the single-country case and hence more public liquidity is needed to drive out private liquidity.
} 
Proposition 6 states the welfare result for the full crowding out case. Since the technical detail of the argument is somewhat tedious, we accelerate the discussion by deferring the formal proof to Section 5.2.1 below, providing here only the outline of the argument together with the basic intuition:

Proposition 6. For $\frac{\theta_{G}^{*}}{\Theta} \geq \sqrt{1-\Psi^{e}}$, it is optimal for the governments of countries $A$ and $B$ to coordinate policies such that: i) Private liquidity is fully crowded out. ii) There is full segmentation if

$$
\frac{\Delta}{\Gamma}>2 \text { and } \frac{\theta_{G}^{*}}{\Theta} \leq \frac{3}{8} \frac{\Delta}{\frac{\Delta}{\Gamma}-\frac{3}{2}},
$$

and zero segmentation otherwise. iii) If $\theta_{G}^{*}>\theta^{\underline{R}}$, where $\theta^{\underline{R}}<\Theta$ is given by (37) below, then the optimal amount of liquidity injection is below tax capacity and always features zero segmentation.

Proof: see section 5.2.1, below.

Given symmetry, the social welfare function, $W_{A}$ (equation (26)), has only two effective arguments (policy instruments): liquidity injection, $\theta_{T}^{*}$, and segmentation, $\theta_{D}^{*}$. (With a certain abuse of notation we keep the symbol $W_{A}$ to denote welfare as a function of $\theta_{T}^{*}$ and $\theta_{D}^{*}$, once substituted into the vector $\boldsymbol{\theta}_{M}^{*}$.) The welfare manifold is concave in $\theta_{T}^{*}$ and reaches a maximum inside the relevant area when $\frac{\Delta}{\Gamma}<1+\frac{\Psi^{e}}{2}$ and is otherwise increasing in $\theta_{T}^{*}$ over the entire relevant area; it is decreasing in $\theta_{D}^{*}$ when $\frac{\Delta}{\Gamma} \leq 2$ and is otherwise convex in $\theta_{D}^{*}$ reaching minima inside the relevant area. Figure 4 illustrates using arrows to indicate the direction in which welfare is increasing in the $\theta_{T}^{*}$ and $\theta_{D}^{*}$ dimensions, and the $\widehat{\theta}_{T}$ and $\breve{\theta}_{D}$ curves to collect maxima and minima (if they exist) in the $\theta_{T}^{*}$ and the $\theta_{D}^{*}$ dimension, respectively; see Section 5.2.1 for full detail. Remember that $W_{A}$ is defined over the "relevant area" as defined by the $\mathcal{L}^{R}$ set. It is represented by the shaded triangle in Figure 4 , so that $\theta_{D}^{*}$ varies from full segmentation, $\theta_{D}^{*}=\theta_{T}^{*}$, to the lower bound $\theta_{D}^{*}=\max \left(0,1-2 \theta_{T}^{*}\right)$ as defined in equation $(22)$. Since welfare is invariant in $\theta_{D}^{*}$ below that lower bound ${ }^{23}$ we call all $\left(\theta_{T}^{*}, \theta_{D}^{*}\right)$ points on the lower bound "zero segmentation", even if $\theta_{D}^{*}>0$.

Figure 4 also plots a $\Psi_{A \vee B}=\Psi^{e}$, which collects pairs of $\frac{1}{\Theta}\left(\theta_{T}^{*}, \theta_{D}^{*}\right)$ such that the probability of crisis is $\Psi^{e}$. For subsequent use we compute:

$$
\left.\frac{d \theta_{D}^{*}}{d \theta_{T}^{*}}\right|_{\Psi_{A \vee B}\left(\boldsymbol{\theta}_{M}^{*}\right)=\Psi^{e}}=2 \frac{\theta_{T}^{*}}{\theta_{D}^{*}}>1
$$

(see Section 5.3 for more intuition). The curve intersects with the upper bound of the relevant area at $\frac{\theta_{T}^{*}}{\Theta}=\sqrt{1-\Psi^{e}}$, to the right of which lies the full crowding out region.

\footnotetext{
${ }^{23}$ See discussion of equation (22) above.
} 
Figure 4: Welfare manifold
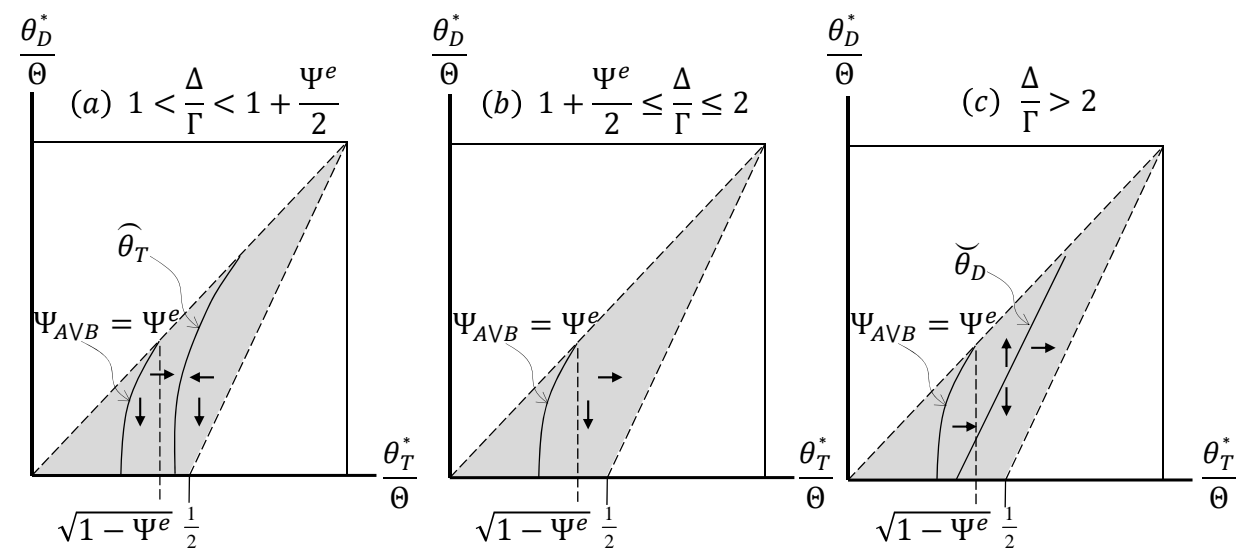

Part $i$ ) of Proposition 6 extends the single-country result of Proposition 3 to the two country case, i.e., if tax capacity allows, it is always optimal to inject sufficient liquidity to fully crowd out the entire supply of private liquidity. The question, then, is whether governments should allow liquidity to flow freely or to segment it.

Part $i$ ) of Proposition 6 provides the answer. The properties of the welfare manifold in the $\theta_{D}^{*}$ dimension already restrict candidates to a segmentation maximum to the corners of the relevant area and to model parameters such that $\frac{\Delta}{\Gamma}>2$. In fact, we can narrow down the set of candidates to segmentation maxima to the case where $\frac{\theta_{G}^{*}}{\Theta}<\frac{1}{2}$. To see why, compare full segmentation with zero segmentation, both with the same binding $G$ constraint, $\frac{\theta_{T}^{*}}{\Theta}=\frac{\theta_{G}^{*}}{\Theta}$; see Figure 5. The probabilities of avoiding a crisis are $\frac{\theta_{G}^{*}}{\Theta}$ and $\frac{1}{2}\left(\frac{2 \theta_{G}^{*}}{\Theta}\right)^{2}$, respectively. Clearly, the former exceeds the latter so that segmentation decreases the overall probability of crisis. Hence, on the balance of probabilities, segmentation makes a positive contribution to welfare. It is still the case, however, that segmentation trades off a mild crisis for a severe one, which makes a negative contribution to welfare. Comparing the value of $W_{A}$ across the two corners of the relevant areas we find out that segmentation is a global maximum for $\frac{\theta_{T}^{*}}{\Theta}=\frac{\theta_{G}^{*}}{\Theta}<\frac{3}{8}<\frac{1}{2}$ (and $\frac{\Delta}{\Gamma}>2$ ). When $\frac{\theta_{G}^{*}}{\Theta}>\frac{1}{2}$ segmentation increases the overall probability of crisis. Adding in the argument regarding the trade-off between mild and severe crisis, segmentation decreases welfare, unambiguously.

Part iii) of Proposition 6 is provided for completeness: unlike in the single-country 
Figure 5: Two countries, full crowding out, free flow versus segmentation when $\frac{\theta_{G}^{*}}{\Theta}<\frac{1}{2}$

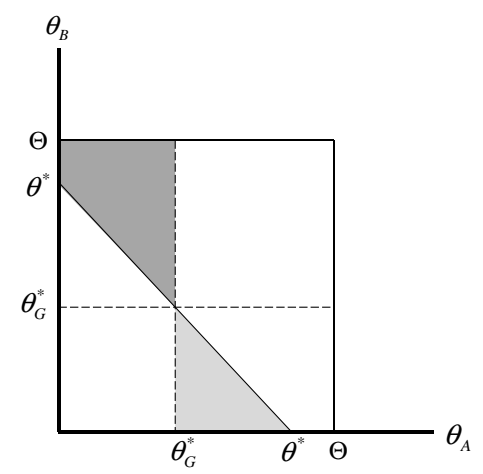

case, in the two country case, even when $\frac{\Delta}{\Gamma}>2$, it is no longer optimal to inject liquidity to bring the probability of crisis down to zero. Intuitively, as total liquidity approaches $2 \Theta$, the crisis probability is so small, see Figure 2, that the benefit of decreasing it further is not sufficient to cover the cost of liquidity.

Technicalities aside, the substantive point of Proposition 6 is that it gives rise to our pecking order result. With fire-sale externalities and financial crisis, the competitive equilibrium is socially inefficient. Policy measures to decrease the probability of crisis are therefore justified on efficiency grounds. Nevertheless, the use of segmentation policies is only justified under very special circumstances. Even when segmentation optima do exist, they will vanish once the $G$ constraint is relaxed sufficiently. Hence, the following rule of thumb may be formulated: to enhance welfare, coordinated governments' first priority should be the injection of subsidized liquidity. Segmentation policies should be considered only when the governments have run out of the tax capacity to inject more liquidity. Even then, segmentation policies are not guaranteed to be welfare enhancing. The reason is rooted in the public good nature of liquidity and, hence, its under provision in a competitive equilibrium. The best way to address such a problem is directly, by injecting more liquidity, rather than indirectly, through segmentation, which has other undesirable implication such as the substitution of mild financial crises by more severe ones. 


\subsubsection{Proof of Proposition 6}

The proof of Proposition 6 draws on a global characterization of the welfare function, $W_{A}$. To that end, we compute the total derivatives of welfare with respect to simultaneous and symmetric variations in, $\theta_{T}^{*}$ and $\theta_{D}^{*}$; remember $\boldsymbol{\theta}_{M}^{*}=\left(\theta_{D}^{*}, \theta_{D}^{*}, \theta_{T}^{*}, 2 \theta_{T}^{*}\right)$. The computation is done through various combinations of the partial derivatives (28) to (31), to account for governments' coordination:any change in policy in country $A$ is matched, simultaneously and symmetrically, by country $B$. Hence,

$$
\begin{gathered}
\frac{\partial W_{A}\left(\boldsymbol{\theta}_{M}^{*}\right)}{\partial \theta_{T}^{*}}=\frac{\partial W_{A}}{\partial \theta_{A, T}^{*}}+2 \frac{\partial W_{A}}{\partial \theta^{*}}=\Gamma\left[2\left(1-\Psi_{A \vee B}\right)\left(\frac{\Delta}{\Gamma}-1\right)+\left(\Psi_{A \vee B}-\Psi^{e}\right)\right] \\
\frac{\partial W_{A}\left(\boldsymbol{\theta}_{M}^{*}\right)}{\partial \theta_{D}^{*}}=\frac{\partial W_{A}}{\partial \theta_{A, D}^{*}}+\frac{\partial W_{A}}{\partial \theta_{B, D}^{*}}=\frac{\theta_{D}^{*}}{\Theta} \Gamma\left[\left(1-2 \frac{2 \theta_{T}^{*}-\theta_{D}^{*}}{\Theta}\right) \frac{\Delta}{\Gamma}-2\left(1-\frac{3}{2} \frac{2 \theta_{T}^{*}-\theta_{D}^{*}}{\Theta}\right)\right] .
\end{gathered}
$$

Lemma 1 provides a comprehensive description of the welfare manifold of the $W_{A}$ function. Note that although the proof of Proposition 6 makes use of the properties of the manifold over just a subspace of the relevant area, $\frac{\theta_{T}^{*}}{\Theta}>\sqrt{1-\Psi^{e}}$, the lemma applies to the entire relevant area, thus supporting much of the subsequent analysis.

Lemma 1. The welfare manifold of the $W_{A}$ function is characterized by the following properties:

i) For any point such that $\Psi_{A \vee B}\left(\boldsymbol{\theta}_{M}^{*}\right)=\Psi^{e}$, welfare is increasing in total liquidity, $\theta_{T}^{*}$.

ii) For $\frac{\Delta}{\Gamma} \in\left(1, \frac{3}{2}\right)$, welfare is concave in total liquidity, $\theta_{T}^{*}$. Iff $\frac{\Delta}{\Gamma}<1+\frac{\Psi^{e}}{2}$, there exists a function $\widehat{\theta}_{T}\left(\theta_{D}^{*}\right)$ such that $\frac{\partial W_{A}\left(\boldsymbol{\theta}_{M}^{*}\right)}{\partial \theta_{T}^{*}}=0$ with $\boldsymbol{\theta}_{M}^{*}=\left(\theta_{D}^{*}, \theta_{D}^{*}, \widehat{\theta}_{T}\left(\theta_{D}^{*}\right), 2 \widehat{\theta}_{T}\left(\theta_{D}^{*}\right)\right) \in \mathcal{L}^{R}$; otherwise, welfare is increasing in $\theta_{T}^{*}$ over the entire relevant area, $\mathcal{L}^{R}$. For $\frac{\Delta}{\Gamma}>\frac{3}{2}$, welfare is convex in $\theta_{T}^{*}$ and increasing over the entire relevant area, $\mathcal{L}^{R}$.

iii) For $\frac{\Delta}{\Gamma}>2$, welfare is convex in segmented liquidity $\theta_{D}^{*}$. There exists a function, $\breve{\theta}_{D}\left(\theta_{T}^{*}\right)=2 \frac{\theta_{T}^{*}}{\Theta}-\frac{\frac{\Delta}{\Gamma}-2}{2\left(\frac{\Delta}{\Gamma}-\frac{3}{2}\right)}$ such that for $\boldsymbol{\theta}_{M}^{*}=\left(\breve{\theta}_{D}\left(\theta_{T}^{*}\right), \breve{\theta}_{D}\left(\theta_{T}^{*}\right), \theta_{T}^{*}, 2 \theta_{T}^{*}\right) \in \mathcal{L}^{R}, \frac{\partial W_{A}\left(\boldsymbol{\theta}_{M}^{*}\right)}{\partial \theta_{D}^{*}}=$ 0 . For $\frac{\Delta}{\Gamma} \in(1,2]$, welfare is concave and decreasing in $\theta_{D}^{*}$ over the entire relevant area, $\mathcal{L}^{R}$.

iv) Welfare is constant in $\theta_{D}^{*}$ for $\boldsymbol{\theta}_{M}^{*} \notin \mathcal{L}^{R}$

Proof see Appendix B.

When $\frac{\Delta}{\Gamma} \leq 1+\frac{\Psi^{e}}{2}$ there exist combinations of $\left(\theta_{T}^{*}, \theta_{D}^{*}\right)$ inside the relevant area such that $\frac{\partial W_{A}\left(\boldsymbol{\theta}_{M}^{*}\right)}{\partial \theta_{T}^{*}}=0$. Since $W_{A}$ is concave in $\theta_{T}^{*}$ when $\frac{\Delta}{\Gamma} \leq 1+\frac{\Psi^{e}}{2}$ (point $i i$ ) of Lemma 1 ), these points correspond to welfare maxima with respect to $\theta_{T}^{*}$ (i.e. changing $\theta_{T}^{*}$ while holding $\theta_{D}^{*}$ constant) and we label the corresponding function by $\theta_{T}\left(\theta_{D}^{*}\right)$. It is homothetic to the $\Psi_{A \vee B}\left(\boldsymbol{\theta}_{M}^{*}\right)=\Psi^{e}$ curve. Hence, in panel $(a)$ the horizontal arrows point towards 
the $\widehat{\theta}_{T}$ curve. Likewise, when $\frac{\Delta}{\Gamma}>2$, there exists a linear $\breve{\theta}_{D}\left(\theta_{T}^{*}\right)$ function such that for any combination $\left(\theta_{T}^{*}, \breve{\theta}_{D}\left(\theta_{T}^{*}\right)\right), \frac{\partial W_{A}\left(\boldsymbol{\theta}_{M}^{*}\right)}{\partial \theta_{D}^{*}}=0$. The $\breve{\theta}_{D}\left(\theta_{T}^{*}\right)$ function is represented by a straight line with a slope of 2 , parallel to the lower bound of the relevant area; see panel (c) of Figure 4. Since $W_{A}$ is convex in $\theta_{D}^{*}$ (see proof of Lemma 1 ), the graph of the $\breve{\theta}_{D}\left(\theta_{T}^{*}\right)$ function collects minima in the $\theta_{D}^{*}$ dimension and the vertical arrows point away from the $\breve{\theta}_{D}$ curve.

Part $i$ ) of Proposition 6 follows immediately from part $i$ ) of Lemma 1 and from Corollary 1.

As for part $i i$ ) of Proposition 6, when $\frac{\Delta}{\Gamma} \leq 2 W_{A}$ is decreasing in $\theta_{D}^{*}$ over the entire relevant area. It follows that zero segmentation is optimal there. When $\frac{\Delta}{\Gamma}>2, W_{A}$ is convex in $\theta_{D}^{*}$ so that the social optimum is a corner solution, with either full or zero segmentation, both with a binding $G$ constraint; see Figure 4. In a segmentation optimum the $G$ constraint must bind, otherwise welfare can be increased by injecting more liquidity, i.e., increasing $\theta_{T}^{*}$, up to the point where either the constraint binds or the lower bound of the relevant area, $\mathcal{L}^{R}$, is reached (with zero segmentation). We search for global optima by comparing the zero and full segmentation corners along the binding $\theta_{G}^{*}$. If $\frac{\theta_{G}^{*}}{\Theta} \leq \frac{1}{2}$, the zero and full segmentation corners are located at $\theta_{D}^{*}=0$ and $\theta_{D}^{*}=\theta_{G}^{*}$, respectively. Substituting into $W_{A}\left(\boldsymbol{\theta}_{M}^{*}\right)$, full segmentation dominates iff

$$
\frac{\Delta}{\Gamma}\left(\frac{4}{3} \frac{\theta_{G}^{*}}{\Theta}-\frac{1}{2}\right) \leq 2 \frac{\theta_{G}^{*}}{\Theta}-1 .
$$

Solving for $\frac{\theta_{G}^{*}}{\Theta}$ yields (32). If $\frac{\theta_{G}^{*}}{\Theta}>\frac{1}{2}$, the zero and full segmentation corners are located at $\frac{\theta_{D}^{*}}{\Theta}=-1+2 \frac{\theta_{G}^{*}}{\Theta}$ (the lower of the relevant area, $\mathcal{L}^{R}$ ) and $\theta_{D}^{*}=\theta_{G}^{*}$. Substituting into $W_{A}\left(\boldsymbol{\theta}_{M}^{*}\right)$ shows that full segmentation is never optimal in this case.

As for part $i i i$ ), when the tax constraint does not bind (we determine below for which tax capacity this is the case), we know that the optimum features zero segmentation. By inspecting the welfare derivative on the lower bound of the relevant area, it can be shown that the welfare function reaches its unconstrained maximum at a value $\frac{\theta_{T}^{*}}{\Theta}<\frac{1}{2}$ if and only if $\frac{\Delta}{\Gamma}<1+\frac{\Psi^{e}}{2}$ and at a value $1>\frac{\theta_{T}^{*}}{\Theta} \geq \frac{1}{2}$ otherwise. The exact value of the maximum can be obtained by substituting $\theta_{D}^{*}=0$ into the welfare derivative (34) when $\frac{\Delta}{\Gamma}<1+\frac{\Psi^{e}}{2}$ and setting it to zero. When $\frac{\Delta}{\Gamma} \geq 1+\frac{\Psi^{e}}{2}$, we compute

$$
\left.\frac{d W_{A}}{d \theta_{T}^{*}}\right|_{\frac{\theta_{D}^{*}}{\Theta}=-1+2 \frac{\theta_{T}^{*}}{\Theta}}=\frac{\partial W_{A}}{\partial \theta_{T}^{*}}+2 \frac{\partial W_{A}}{\partial \theta_{D}^{*}}
$$


and substitute $\frac{\theta_{D}^{*}}{\Theta}=-1+2 \frac{\theta_{T}^{*}}{\Theta}$ into the corresponding welfare derivatives. Doing so yields

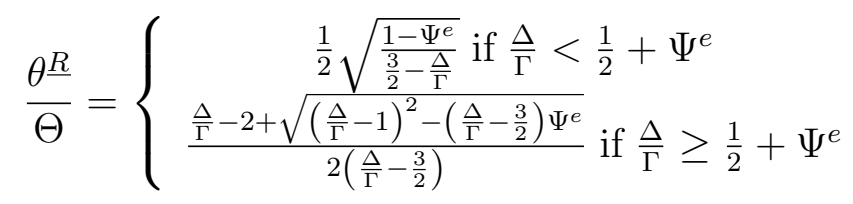

\subsection{Partial crowding out $\left(0<\frac{\theta_{G}^{*}}{\Theta}<\sqrt{1-\Psi^{e}}\right)$}

We complete the analysis with the $0<\frac{\theta_{G}^{*}}{\Theta}<\sqrt{1-\Psi^{e}}$ case, where the tax capacity is too low to fully crowd out private liquidity. The following regimes are conceivable.

First, the governments can coordinate policies that allow both private and public liquidity to flow freely. By a similar argument to that in Proposition 2, as long as the speculators still participate in the liquidity markets, the injection of free-flowing liquidity is ineffective because public liquidity crowds out, one for one, private liquidity with no effect on total liquidity or the probability of crisis.

Second, the governments can inject segmented or free-flowing liquidity and at the same time restrict the free flow of private liquidity. Proposition 7 below demonstrates that such a policy is sub-optimal.

Finally, the governments can inject segmented liquidity and, at the same time, allow the free flow of private liquidity. If speculators participate, the probability of crisis, $\Psi_{A \vee B}$, must be $\Psi^{e}$, which allows them to break even. Note that, in this case, segmented liquidity, which can be used only domestically, is an imperfect substitute to free-flowing liquidity that can be used in both countries. As a result, the injection of public (segmented) liquidity crowds out some private (free-flowing) liquidity, but less than one for one; see the derivative (33) of the implicit function $\Psi_{A \vee B}\left(\boldsymbol{\theta}_{M}^{*}\right)=\Psi^{e}$. Diagrammatically, such a policy can be illustrated as a movement along the $\Psi_{A \vee B}=\Psi^{e}$ curve in Figure 4, where the injection of segmented public liquidity, $\theta_{D}^{*}$, boosts the total amount of liquidity (private and public), $\theta_{T}^{*}$, which provides an extra motive for a segmentation policy. Hence,

Proposition 7. Suppose $0<\frac{\theta_{G}^{*}}{\Theta}<\sqrt{1-\Psi^{e}}$. It is optimal for the governments of countries $A$ and $B$ to coordinate policies such that

i) No private liquidity is ever segmented (so that $\theta_{D}^{*}$ below applies to public segmented liquidity alone).

ii) Condition (32) from Proposition 6 is sufficient but no longer necessary for segmentation to be optimal. There are parameter values such that condition (32) is not satisfied but it is still optimal for the governments to inject segmented liquidity $\left(\theta_{D}^{*}>0\right)$.

(iii) There are parameter values such that governments supply public liquidity but do not segment it. 
Proof. See Appendix B.

The intuition for Part $i$ ) of Proposition 7 is the following: given a certain level of segmented public liquidity, $\theta_{D}^{*}$, restricting the free flow of private liquidity implies that total liquidity falls; the policy shifts the equilibrium from the $\Psi_{A \vee B}=\Psi^{e}$ curve, leftwards. By part $i$ ) of Lemma 1 the welfare manifold is increasing in total liquidity (see arrows in Figure 4), so the policy is welfare decreasing. Note also that such a policy would increase the probability of crisis and, therefore, "earn" the governments a higher rate of return, even higher than the speculators' rate of return, $\rho$. That is, instead of subsidizing liquidity, the governments would impose a tax, which is contrary to our line of argument so far.

For part ii) of Proposition 7, that the injection of segmented liquidity boosts total liquidity, it gives governments an additional motive to segment, over and above the level implied by equation (32) in Proposition 6. As a result, condition (32), which was necessary and sufficient for segmentation under full crowding out, becomes sufficient but not necessary under partial crowding out. Technically, there are some (not all!) parameter values $\left(\Delta, \Gamma, \Psi^{e}\right)$ where segmentation of public liquidity is sub-optimal if $\frac{\theta_{G}^{*}}{\Theta}>\sqrt{1-\Psi^{e}}$ but is optimal once the inequality is reversed. Clearly, the liquidity boosting effect is active, but not sufficiently strong to dominate globally. In particular, consider the case where $\frac{\Delta}{\Gamma}<2$. Where $\frac{\theta_{G}^{*}}{\Theta}>\sqrt{1-\Psi^{e}}$ (full crowding out) the optimal policy (unambiguously) is to switch from segmented to free-flowing public liquidity, but leave the total amount of liquidity at the same level. But where $\frac{\theta_{G}^{*}}{\Theta}<\sqrt{1-\Psi^{e}}$ (partial crowding out), it is no longer possible to decrease the amount of segmented public liquidity but leave the total amount of liquidity intact: moving along the $\Psi_{A \vee B}\left(\boldsymbol{\theta}_{M}^{*}\right)=\Psi^{e}$ curve, as the governments inject less segmented liquidity, total liquidity also drops. As a result, some level of segmentation might be optimal.

For part iii) of Proposition 7, it might be optimal for the governments to inject liquidity but to avoid segmentation altogether (along the horizontal axis in Figure 4). Doing so, the governments push the probability of crisis below $\Psi^{e}$, so the speculators no longer wish to participate in the liquidity market. (They are crowded out rather than restricted from participating.) As a result, total liquidity decreases. However, we show that such a policy is optimal when $\frac{\theta_{G}^{*}}{\Theta}$ approaches $\sqrt{1-\Psi^{e}}$ from below. For then, the welfare gain from pooling public liquidity compensates for the (small) drop in total liquidity.

\subsection{Implications}

Proposition 8 consolidates the main results of Sections 5.2 to 5.3 into our key "pecking order" result for market segmentation:

Proposition 8. (i) It is never optimal to segment private liquidity. 
(ii) The injection of segmented public liquidity is sometimes optimal. If $\left(\frac{\theta_{G}^{*}}{\Theta} \geq \sqrt{1-\Psi^{e}}\right)$, then condition (32) provides a necessary and sufficient condition for optimal segmentation. If $\left(\frac{\theta_{G}^{*}}{\Theta}<\sqrt{1-\Psi^{e}}\right)$, then condition (32) is sufficient but not necessary for the optimality of segmentation.

(iii) Whenever parameter values $\left(\Delta, \Gamma, \Psi^{e}\right)$ and tax capacity $\theta_{G}^{*}$ are such that the injection of segmented public liquidity is optimal, a sufficiently large increase in tax capacity makes the segmentation of public liquidity sub-optimal.

Proof. Parts $i$ ) and ii) of Proposition 8 are immediate. For part iii), by part $i$ ) of Lemma 1 , within the partial crowding out regime, if the governments could increase the amount of total liquidity, keeping segmented liquidity constant, i.e., moving leftwards off any point on the $\Psi_{A \vee B}=\Psi^{e}$ curve, then welfare would increase. Such a move is not feasible when the $G$ constraint binds, but is feasible once the constraint is sufficiently relaxed. Once in the region where $\Psi_{A \vee B}<\Psi^{e}$, to the right of the $\Psi_{A \vee B}=\Psi^{e}$ curve, condition (32) in Proposition 6 applies.

The pecking order result means that segmentation policies are dominated by liquidity injection policies, as long as these are not constrained by tax capacity. Coordinated governments may segment their own injected liquidity only when tax capacity constrains them from dealing with the public good aspect of liquidity directly, by enhancing the supply of public liquidity. That segmentation is only a poor substitute to liquidity injection is due to the policy's inherent inefficiency: it leaves underutilized liquidity that could be used to fend off a severe financial crisis, while its contagion avoidance benefit is effective only against a mild financial crisis. Even in those cases where the use of segmentation policies is welfare-enhancing, the policy should be applied to public liquidity alone, never restricting the free flow of private liquidity.

\section{$6 \quad$ Uncoordinated policies}

In this section, we characterize Nash equilibria where both governments choose a mix of liquidity injection and segmentation policies without coordination. That is, we depart from the assumption made in Section 5 that any change in country $A$ 's policies is matched, simultaneously and symmetrically, by country $B$. Otherwise, the setting is identical to that of Section 5; that is, policy decisions are taken ex ante, at $t=0$, simultaneously. Policy decisions are announced and the governments commit to execute them as planned. The analysis covers the same three cases that are identified in Section 5, with zero, high and medium tax capacity. The main result is that a lack of coordination results in (weak) excess segmentation: 
Proposition 9. i) It is never part of a Nash equilibrium to segment private liquidity. ii) The Nash equilibrium features excess segmentation in the following sense: For parameter values such that coordinated governments segment public liquidity, they also segment public liquidity when not coordinated, in a Nash equilibrium, but the opposite is not true. That is, there are parameter values such that coordinated governments do not segment public liquidity but uncoordinated governments do.

Proof. See Appendix B.

The easiest way to convey the intuition of part $i$ ) of Proposition 9 is by examining the special case where $G=0$ so that the governments' only decision is whether to segment private liquidity. Consider the response of country $A$, for example, to the various strategies of country $B$. Suppose country $B$ plays free flow. A response by country $A$ to segment is ineffective: by Corollary 1 , country $A$ 's speculators cannot break even so they withdraw from the market. But then, country $A^{\prime} s$ market is serviced by country $B$ 's speculators. It follows that any attempt by country $A$ to create a domestic liquidity buffer through segmentation is futile. Suppose, next, that country $B$ plays segmentation. If country $A$ responds by playing segmentation, it imposes a segmentation regime on both countries. By Proposition 5) the result is to decrease its own welfare, as well as its neighbour's. It follows that segmentation is a weakly dominated strategy when $G=0$.

To convey the intuition of part $i i$ ) we focus on the Nash equilibrium in the case of full crowding out. Consider, again, the case where country $B$ plays free flow. If country $A$ responds by playing segmentation it captures the benefit of avoiding crisis when $\theta_{A} \leq \theta_{G}^{*}$ and $\theta_{B}>\theta_{G}^{*}$ and, at the same time, benefit from an inflow of liquidity from country $B$ when $\theta_{A} \in\left(\frac{\theta_{G}^{*}}{\Theta}, 2 \frac{\theta_{G}^{*}}{\Theta}\right]$ and $\theta_{B}<\theta_{G}^{*}$. In terms of Figure 5 , it can capture the lightly shaded triangle without losing the darkly shaded trapezoid.

On a more heuristic level, the results can be motivated by the public-good property of liquidity. When the governments have no capacity to provide the good themselves, they should at least refrain from undermining (second-best) competitive supply. However, when governments do have the capacity to provide the good themselves, they have an incentive to prevent others from free-riding on it. That is, the beggar-thy-neighbour problem arises only when the liquidity market is taken over by the governments.

\section{Concluding remarks}

Classic results in economics imply that, in a frictionless world, free flow of goods, services and financial securities constitute a necessary condition for an efficient allocation. Some, such as Stiglitz (2010), have stipulated a dramatic reversal of the results in a world prone to financial crisis and contagion. Using a micro-founded model of financial crisis driven by 
leverage and fire sales, we note some inherent inefficiencies associated with a segmentation policy.

We show that segmentation leaves underutilized liquidity that, had it been allowed to flow freely, could have been used in order to fend off a severe financial crisis. At the same time, the benefit of segmentation is in avoiding contagion and withstand only a mild financial crisis. In our model, the welfare cost of crisis increases with the severity of the underlying shock, rendering the trade off introduced by segmentation unfavourable. Nonetheless, segmentation of public liquidity can be welfare-enhancing in some cases, but only as a second best measure, once the direct measure of liquidity injections is constrained from resolving the inherent externalities that plague the liquidity market. Our analysis can be neatly summarized in a pecking order result for segmentation.

Segmentation is a generic concept, relevant beyond the context of international finance. This concept includes, for example, policies such as separating different types of banking activities or imposing constraints on the ability of one financial institution to use its liquidity to trade with another financial institution. Needless to say, our analysis addresses a special case, both in terms of the application and in terms of the modelling choices that we make. Nevertheless, we believe that some of the insights are quite general. First, segmentation is likely to swap a less severe crisis for a more severe one, an effect that is likely to be negative in other micro-founded settings. Second, any benefit of segmentation is likely to be attenuated once analyzed within a general equilibrium setting and once public liquidity injections are added to the policy mix. It will be instructive to adapt the main ideas contained in this paper to other applications, for example, the desirability of mutualizing deposit insurance schemes internationally, or the effect of requiring multinational banks to be capitalized at the subsidiary rather than the holding company level.

Lastly, our paper may shed some new light on issues discussed in certain policy circles regarding the world's financial architecture. For example, the idea that short-term capital flows may be undesirable has become much more acceptable following the 2008 financial crisis. At the same time, the role of governments and central banks in the provision of liquidity has vastly expanded. We suggest that the two developments may be related along the lines of Section 6 above: having gained a dominant position in the liquidity market, uncoordinated governments use segmentation as a means to limit foreign governments from free-riding on the public good that they provide. The analysis in Section 4 suggest that this issue may be a coordination failure: if the governments could commit to avoid segmentation, then welfare might be enhanced. 


\section{APPENDIX A}

\section{Proof of rest of Proposition 1}

We prove that conjectures (5) and (4) hold in equilibrium by demonstrating that any single-investor deviation, $\widetilde{k}, \widetilde{R}^{s}, \widetilde{\lambda}_{u}^{s}, \widetilde{\lambda}_{d}^{s}$, etc., from the equilibrium behavior, $k, R, \lambda^{s}$, given equilibrium prices and allocations, $q^{s}$ and any probability of crisis $\Psi \leq \Psi^{e}$, are sub-optimal.

We proceed by proving the following sequence of claims:

Claim 1: Operating at a scale $\widetilde{k}>k$ is sub-optimal.

Claim 2: All fire sales are executed at market prices; state contingent debt repayments are sub-optimal.

Claim 3: Hoarding liquidity, such that $\widetilde{k}<b+w$, is sub-optimal.

Claim 4: Operating at a scale $\widetilde{k}<k$ is sub-optimal.

Claim 5: The investor's participation constraint is satisfied.

The joint distribution of the macro events, $n, c$ and the liquidity shocks, $u, d$ is described in Table 1.

Table 1: The joint distribution of macro and individual shocks

\begin{tabular}{|l|c|c|c|}
\hline & $n$ & $c$ & total \\
\hline no distress, $u$ & $\psi_{u}^{n} \equiv(1-\Psi)-\frac{\Theta}{2}(1-\Psi)^{2}$ & $\psi_{u}^{c} \equiv \Psi-\frac{\Theta}{2}\left[1-(1-\Psi)^{2}\right]$ & $1-\frac{\Theta}{2}$ \\
\hline distress, $d$ & $\psi_{d}^{n} \equiv \frac{\Theta}{2}(1-\Psi)^{2}$ & $\psi_{d}^{c} \equiv \frac{\Theta}{2}\left[1-(1-\Psi)^{2}\right]$ & $\frac{\Theta}{2}$ \\
\hline total & $1-\Psi$ & $\Psi$ & 1 \\
\hline
\end{tabular}

\section{Proof of Claim $1(\widetilde{k}>k$ is sub-optimal)}

For $\widetilde{k}>k$, the investor has to sell some capital even when he is not in distress in order to meet the debt repayment. The fraction of capital $\widetilde{\lambda}_{u}^{s}$ to be sold is given by $\widetilde{\lambda}_{u}^{s} \widetilde{k} q^{s}+$ $\left(1-\widetilde{\lambda}_{u}^{s}\right) \widetilde{k} y_{2}=\widetilde{R}$.

In case of distress, the amount of fire sales is determined by equation (7), as before. It follows that

$$
\widetilde{\lambda}_{u}^{s}=\frac{\rho-y_{2}}{q^{s}-y_{2}}-\rho \frac{w}{\widetilde{k}\left(q^{s}-y_{2}\right)}, \quad \widetilde{\lambda}_{d}^{s}=\frac{\rho-y_{2}+m}{q^{s}-y_{2}+m}-\rho \frac{w}{\widetilde{k}\left(q^{s}-y_{2}+m\right)} .
$$

The investor's expected payoff is thus

$$
\psi_{u}^{n}\left(1-\lambda_{u}^{n}\right) \widetilde{k} y_{3}+\psi_{u}^{c}\left(1-\lambda_{u}^{c}\right) \widetilde{k} y_{3}+\psi_{d}^{n}\left(1-\lambda_{d}^{n}\right) \widetilde{k} y_{3}+\psi_{d}^{c}\left(1-\lambda_{d}^{c}\right) \widetilde{k} y_{3} .
$$


Substituting $\widetilde{\lambda}_{u}^{s}$ and $\widetilde{\lambda}_{d}^{s}$ and differentiating with respect to $\widetilde{k}$, we derive a condition for the sub-optimality of $\widetilde{k}>k$,

$$
\psi_{u}^{n} \frac{q^{n}-\rho}{q^{n}-y_{2}} y_{3}+\psi_{u}^{c} \frac{q^{c}-\rho}{q^{c}-y_{2}} y_{3}+\psi_{d}^{n} \frac{q^{n}-\rho}{q^{n}-y_{2}+m} y_{3}+\psi_{d}^{c} \frac{q^{c}-\rho}{q^{c}-y_{2}+m} y_{3}<0,
$$

which is satisfied since $q^{n}>q^{c}$ and because $\rho>q^{n}$ by parametric assumption $A 2$.

\section{Proof of Claim 2 (indexation of debt repayments is sub-optimal)}

We start with an arbitrage argument in the spirit of Bhattacharya and Gale (1987) to rule out contracts that separate distressed from non-distressed investors, thereby providing insurance against financial distress. Suppose a third party, or perhaps the lender himself, guarantees a fire sale transfer price different from the market price. Effectively, such a contract is a put option. It would be exercised whenever the strike price exceeds the market price, regardless of whether the investor is distressed. Both ways, he would buy capital goods on the fire sale market at a low price and exercise the option. Note that the assumptions made in Section 2 about the investor's portfolio opacity play an important role in this argument: if capital goods could be tagged, and if the insurer could commit to buying back only items originating in the investor's own project, then the contract could be implemented. A direct observation on down scaling would have a similar effect.

Though put options cannot separate distressed from non-distressed investors, they can still be used in order to make transfers, contingent on macro realizations, from speculators to investors. As such, they are equivalent to debt indexation. Suppose, by way of contradiction, a contract $R(\theta)$. The proof proceeds by showing that there is no interval of $\theta$ on which it would be optimal to set a lower payment than $R=k y_{2}$. It follows from (7) that a rebate $R(\theta)<k y_{2}$ is more valuable when the price of capital is low, i.e., at $q^{c}$ : the rebate offers insurance against selling into an illiquid market. Moreover, $\theta$ affects an investor's payoff only via its effect on the price of the productive assets. For an individual investor it therefore does not matter in which of the crisis states the rebate is granted. Finally, since the rebate is fairly priced, and payoffs are linear in project scale, an investor will either choose no rebate, or a rebate in all crisis states. We therefore now focus, w.l.o.g. on the case where a constant rebate in all crisis states is granted. We denote the repayment in the crisis and non-crisis states by $\widetilde{R}^{c}<\widetilde{R}^{n}$. The lender's participation constraint,

$$
(1-\Psi) \widetilde{R}^{n}+\Psi \widetilde{R}^{c}=\rho(\widetilde{k}-w)
$$

has to be satisfied. Since it is still optimal to scale up to the limit that can be afforded 
by a non-distressed investor, we have $\widetilde{R}^{n}=\widetilde{k} y_{2}$, and hence,

$$
\widetilde{R}^{c}=\widetilde{k} y_{2}-\frac{\rho w-\widetilde{k}\left(\rho-y_{2}\right)}{\Psi} .
$$

Clearly, $\widetilde{k}<k$. The $\lambda$ s are still determined by (7), so

$$
\widetilde{\lambda}^{n}=\lambda^{n}, \quad \tilde{\lambda}^{c}=\frac{m-\frac{1}{\Psi}\left[\rho \frac{w}{\tilde{k}}-\left(\rho-y_{2}\right)\right]}{q^{c}-y_{2}+m} .
$$

Note that this policy leaves the investor with a slack, $\widetilde{k} y_{2}-\tilde{R}^{c}$, if he is not distressed while the economy is in financial crisis. Substituting the above expressions into the investor's expected payoff,

$\psi_{u}^{n} \widetilde{k} y_{3}+\psi_{u}^{c}\left[\widetilde{k} y_{3}+\frac{\rho w-\widetilde{k}\left(\rho-y_{2}\right)}{\Psi}\right]+\psi_{d}^{n} \frac{q^{n}-y_{2}}{q^{n}-y_{2}+m} \widetilde{k} y_{3}+\psi_{d}^{c} \frac{q^{c}-y_{2}+\frac{1}{\Psi}\left[\rho \frac{w}{\widetilde{k}}-\left(\rho-y_{2}\right)\right]}{q^{c}-y_{2}+m} \widetilde{k} y_{3}$,

and differentiating with respect to $\widetilde{k}$, we derive a condition for the sub-optimality of the $\widetilde{R}^{c}<\widetilde{R}^{n}$ policy (in the $\widetilde{k}<k$ region),

$$
\psi_{u}^{n} y_{3}+\psi_{u}^{c}\left(y_{3}-\frac{\rho-y_{2}}{\Psi}\right)+\psi_{d}^{n} \frac{q^{n}-y_{2}}{q^{n}-y_{2}+m} y_{3}+\psi_{d}^{c} \frac{q^{c}-y_{2}-\frac{1}{\Psi}\left(\rho-y_{2}\right)}{q^{c}-y_{2}+m} y_{3} \geq 0 .
$$

Solving the inequality for $\rho$, using the unconditional probability of distress $\psi_{d}^{n}+\psi_{d}^{c}=\frac{\Theta}{2}$ and $\psi_{u}^{c}+\psi_{d}^{c}=\Psi$, we obtain

$$
\rho \leq y_{2}+y_{3} \frac{1-\frac{\Theta}{2} \lambda^{n}-\psi_{d}^{c}\left(\lambda^{c}-\lambda^{n}\right)}{1+\frac{\psi_{d}^{c}}{\Psi}\left(\frac{y_{3}}{\frac{m}{1-\gamma}}-1\right)}
$$

This can be written as

$$
\rho \leq y_{2}+y_{3} \frac{1-\frac{\Theta}{2} \lambda^{n}-\frac{\Theta}{2} \Psi(2-\Psi)\left(\lambda^{c}-\lambda^{n}\right)}{1+\frac{\Theta}{2}(2-\Psi)\left(\frac{y_{3}}{\frac{m}{1-\gamma}}-1\right)} .
$$

Notice that the numerator of the term on $y_{3}$ is lowest when $\Psi=1$, while the denominator is highest when $\Psi=0$. It thus follows that

$$
\frac{1-\frac{\Theta}{2} \lambda^{n}-\frac{\Theta}{2} \Psi(2-\Psi)\left(\lambda^{c}-\lambda^{n}\right)}{1+\frac{\Theta}{2}(2-\Psi)\left(\frac{y_{3}}{\frac{m}{1-\gamma}}-1\right)}>\frac{1-\frac{\Theta}{2} \lambda^{c}}{1+\Theta\left(\frac{y_{3}}{\frac{m}{1-\gamma}}-1\right)},
$$

and thus, parametric assumption $A 4$ is a sufficient condition. 


\section{Proof of Claim 3 (hoarding liquidity is sub-optimal):}

Suppose that an investor sets aside liquidity, $\widetilde{l}=w+\widetilde{b}-\widetilde{k}>0$, while still borrowing up to $\widetilde{R}=\widetilde{k} y_{2}$ and $\widetilde{R}=\rho \widetilde{b}$. Using (3), it follows that

$$
\widetilde{l}=w-\widetilde{k}\left(\frac{\rho-y_{2}}{\rho}\right)
$$

That provides him with an extra resource to fund maintenance and debt repayments and moderate fire sales. Instead of equation $(7), \widetilde{\lambda}_{d}^{s}$ is determined by

$$
\widetilde{\lambda}_{d}^{s} q^{s} \widetilde{k}+\left(1-\widetilde{\lambda}_{d}^{s}\right) y_{2} \widetilde{k}+w-\widetilde{k}\left(\frac{\rho-y_{2}}{\rho}\right)=\left(1-\widetilde{\lambda}_{d}^{s}\right) m+\widetilde{R}
$$

Additionally, the investor would turn into a liquidity supplier if he is not distressed:

$$
y_{u}^{s}=\widetilde{k} y_{3}+r^{s}\left[w-\widetilde{k}\left(\frac{\rho-y_{2}}{\rho}\right)\right]
$$

Substituting the above expressions in the investor's expected payoff and differentiating with respect to $\widetilde{k}$, we derive a condition for the sub-optimality of the hoarding policy (in the $\widetilde{k}<k$ region):

$$
\psi_{u}^{n}\left(y_{3}-\frac{\rho-y_{2}}{\rho}\right)+\psi_{u}^{c}\left(y_{3}-\frac{\rho-y_{2}}{\rho} r^{c}\right)+\psi_{d}^{n} \frac{q^{n}-y_{2}-\frac{\rho-y_{2}}{\rho}}{q^{n}-y_{2}+m} y_{3}+\psi_{d}^{c} \frac{q^{c}-y_{2}-\frac{\rho-y_{2}}{\rho}}{q^{c}-y_{2}+m} y_{3} \geq 0
$$

To prove that condition (39) holds, we subtract the LHS of inequality (38) from the LHS of inequality (39) and show that the result is positive:

$$
\left(\rho-y_{2}\right)\left[\psi_{u}^{n}\left(-\frac{1}{\rho}\right)+\psi_{u}^{c}\left(-\frac{r^{c}}{\rho}+\frac{1}{\Psi}\right)+\psi_{d}^{n} \frac{-\frac{1}{\rho}}{q^{n}-y_{2}+m} y_{3}+\psi_{d}^{c} \frac{-\frac{1}{\rho}+\frac{1}{\Psi}}{q^{c}-y_{2}+m} y_{3}\right] \geq 0 .
$$

By parametric assumptions $A 1$ and $A 2$, it follows that $\rho-y_{2}>0$. Since we consider only $\Psi<\Psi^{e}$, and since $r^{c}=\left(\rho-1+\Psi^{e}\right) / \Psi^{e}$ is decreasing in $\Psi^{e}$, we can derive a sufficient condition by replacing $r^{c}$ with an upper bound $(\rho-1+\Psi) / \Psi \geq r^{c}$. Using the expressions for $q^{n}$ and $q^{c}$, and using parametric assumption $A 1$ once again, we reduce the above to the sufficient condition

$$
\psi_{u}^{n}(-1)+\psi_{u}^{c}\left(\frac{1-\Psi}{\Psi}\right)+\psi_{d}^{n}\left(-\frac{1}{\delta}\right)+\psi_{d}^{c}\left(\frac{-\Psi+\rho}{\Psi}\right) \frac{1}{\delta} \geq 0 .
$$

Substituting the $\psi$ s from the joint-distribution table above, this simplifies to

$$
\left(\frac{1}{\delta}-1\right)(1-\Psi) \Psi+\left[1-(1-\Psi)^{2}\right] \frac{\rho-1}{\delta}>0
$$


which is true.

\section{Proof of Claim 4 (Operating at a scale $\widetilde{k}<k$ is sub-optimal)}

Suppose that an investor operates at a scale $w<\widetilde{k}<k$ and thus borrows an amount $0<\widetilde{b}<k-w$. In that case, the required repayment $\widetilde{R}=\rho \widetilde{b}<\widetilde{k} y_{2}$ leaves the nondistressed investor with spare period-2 income:

$$
y_{u}^{s}=\widetilde{k} y_{3}+\widetilde{k} y_{2}-\widetilde{R}=\widetilde{k} y_{3}+\widetilde{k} y_{2}-\rho(\widetilde{k}-w) \text {. }
$$

For the distressed investor, the $\lambda$ s are determined by

$$
\widetilde{\lambda}_{d}^{s} q^{s} \widetilde{k}+\left(1-\widetilde{\lambda}_{d}^{s}\right) \widetilde{k} y_{2}=\left(1-\widetilde{\lambda}_{d}^{s}\right) m \widetilde{k}+\rho(\widetilde{k}-w)
$$

Substituting the above expressions in the investor's expected payoff and differentiating with respect to $\widetilde{k}$, we derive a condition for the sub-optimality of this policy:

$$
\left(\psi_{u}^{n}+\psi_{u}^{c}\right)\left(y_{2}+y_{3}-\rho\right)+\psi_{d}^{n} \frac{q^{n}-\rho}{q^{n}-y_{2}+m} y_{3}+\psi_{d}^{c} \frac{q^{c}-\rho}{q^{c}-y_{2}+m} y_{3} \geq 0 .
$$

To prove that condition (40) holds, we subtract the LHS of inequality (38) from the LHS of inequality (40) and show that the result is positive:

$$
\left(\rho-y_{2}\right)\left[\psi_{u}^{n}(-1)+\psi_{u}^{c}\left(-1+\frac{1}{\Psi}\right)-\psi_{d}^{n} \frac{1}{q^{n}-y_{2}+m} y_{3}+\psi_{d}^{c} \frac{-1+\frac{1}{\psi}}{q^{c}-y_{2}+m} y_{3}\right] \geq 0
$$

From assumptions $A 1$ and $A 2$, it follows that $\rho-y_{2}>0$. Using the expressions for $q^{n}$ and $q^{c}$, and using assumption $A 1$ once again, we reduce the above to the sufficient condition

$$
\psi_{u}^{n}(-1)+\psi_{u}^{c}\left(\frac{1-\Psi}{\Psi}\right)-\psi_{d}^{n} \frac{1}{\delta}+\psi_{d}^{c}\left(\frac{1-\Psi}{\Psi}\right) \frac{1}{\delta} \geq 0
$$

which reduces after the substitution of the $\psi$ s (from the joint-distribution table above) to

$$
\left(\frac{1}{\delta}-1\right) \Psi \geq 0
$$

\section{Proof of claim 5 (the investor's participation constrained is satisfied)}

Substituting project size $k=w \frac{\rho}{\rho-y_{2}}$ into the expected payoff and solving for $\rho$ yields

$$
\rho \leq y_{2}+y_{3}\left[\psi_{u}^{n}+\psi_{u}^{c}+\psi_{d}^{n}\left(1-\frac{m}{\delta y_{3}}\right)+\psi_{d}^{c} \gamma\right]
$$


Since $1-\frac{m}{\delta y_{3}} \geq \gamma$ (and using the $\psi$ s from the joint distribution function above), that can be reduced to the sufficient condition

$$
\rho \leq y_{2}+y_{3}\left[1-(1-\gamma) \frac{\Theta}{2}\right]
$$

which is implied by assumption $A 4$. 


\section{APPENDIX B}

\section{Proof of Lemma 1}

i) That welfare is increasing in $\theta_{T}^{*}$ for any combination of $\left(\theta_{T}^{*}, \theta_{D}^{*}\right)$ such that $\Psi_{A \vee B}\left(\boldsymbol{\theta}_{M}^{*}\right)=$ $\Psi^{e}$ follows immediately from equation (34) and the fact that $\frac{\Delta}{\Gamma}>1$.

ii) For concavity, compute

$$
\frac{\partial}{\partial \theta_{T}^{*}} \frac{\partial W_{A}}{\partial \theta_{T}^{*}}=2 \Gamma\left(\frac{3}{2}-\frac{\Delta}{\Gamma}\right) \frac{\partial \Psi_{A \vee B}}{\partial \theta_{T}^{*}} .
$$

and notice that the second derivative (42) is negative for $\frac{\Delta}{\Gamma} \in\left(1, \frac{3}{2}\right)$. Note that the derivative (34) is a function of $\theta_{T}^{*}$ and $\theta_{D}^{*}$ only via $\Psi_{A \vee B}\left(\boldsymbol{\theta}_{M}^{*}\right)$. To find $\widehat{\theta}_{T}\left(\theta_{D}^{*}\right)$ just set the derivative (34) equal to zero and solve for $\Psi_{A \vee B}$, which yields the solution $\widehat{\Psi}_{T}=\frac{\Psi^{e}-2\left(\frac{\Delta}{\Gamma}-1\right)}{1-2\left(\frac{\Delta}{\Gamma}-1\right)}$ and implicitly provides $\widehat{\theta}_{T}\left(\theta_{D}^{*}\right)$. Notice that on the interval $\frac{\Delta}{\Gamma} \in\left(1, \frac{3}{2}\right), \widehat{\Psi}_{T}$ is positive only if $\frac{\Delta}{\Gamma}<1+\frac{\Psi^{e}}{2}$. For $\frac{\Delta}{\Gamma} \in\left(1+\frac{\Psi^{e}}{2}, \frac{3}{2}\right)$ the derivative (34) is positive for any $\Psi_{A \vee B}\left(\boldsymbol{\theta}_{M}^{*}\right) \geq 0$. If $\frac{\Delta}{\Gamma}>\frac{3}{2}$, welfare is convex in $\theta_{T}^{*}$ and since it is increasing for $\Psi_{A \vee B}\left(\boldsymbol{\theta}_{M}^{*}\right)=\Psi^{e}$ it is also increasing for the entire relevant area, $\mathcal{L}^{R}$.

iii) We rewrite the derivative (35) as

$$
\frac{\partial W_{A}}{\partial \theta_{D}^{*}}=\frac{\theta_{D}^{*}}{\Theta} \Gamma\left[2\left(\frac{\Delta}{\Gamma}-\frac{3}{2}\right) \frac{\theta_{D}^{*}-2 \theta_{T}^{*}}{\Theta}+\frac{\Delta}{\Gamma}-2\right] .
$$

If $\frac{\Delta}{\Gamma} \leq 2$ then the above expression is negative over the entire relevant area. For $\frac{\Delta}{\Gamma}>2$ we set the derivative (43) equal to zero and solve out for any $\theta_{T}^{*}$ to derive the function:

$$
\breve{\theta}_{D}\left(\theta_{T}^{*}\right)=2 \frac{\theta_{T}^{*}}{\Theta}-\frac{\frac{\Delta}{\Gamma}-2}{2\left(\frac{\Delta}{\Gamma}-\frac{3}{2}\right)} .
$$

We also compute the second derivative of the welfare function with respect to $\theta_{D}^{*}$ :

$$
\frac{\partial}{\partial \theta_{D}^{*}} \frac{\partial W_{A}}{\partial \theta_{D}^{*}}=\frac{1}{\theta_{D}^{*}} \frac{\partial W_{A}}{\partial \theta_{D}^{*}}+2 \Gamma \frac{\theta_{D}^{*}}{\Theta^{2}}\left(\frac{\Delta}{\Gamma}-\frac{3}{2}\right) .
$$

From (45), we can see that the welfare function is locally convex in $\theta_{D}^{*}$ for any point on $\breve{\theta}_{D}\left(\theta_{T}^{*}\right)$. Notice that $\breve{\theta}_{D}\left(\theta_{T}^{*}\right)$ function is a complete description of the points where the derivative (43) changes sign.

$i v)$ Suppose $\theta_{D}^{*}<2 \theta_{T}^{*}-\Theta$. For any realization such that $\theta_{A}+\theta_{B} \leq \theta^{*}\left(\right.$ remember $\left.\theta^{*}=2 \theta_{T}^{*}\right)$ there is sufficient liquidity in the world to avoid a financial crisis in both countries; for any realization such that $\theta_{A}+\theta_{B}>\theta^{*}$, both countries suffer a financial crisis. Hence, for any realization $\left(\theta_{A}, \theta_{B}\right)$, a "small" increase in $\theta_{D}^{*}$ will affect neither the incidence of financial crisis nor social welfare. 


\section{Proof of Proposition 7}

i) Let $\underline{\theta}_{T}^{*}$ be defined by $\Psi_{i}\left(0,0, \underline{\theta}_{T}^{*}, \underline{\theta}_{T}^{*}\right)=\Psi^{e}$ so that $\left(\underline{\theta}_{T}^{*}, 0\right)$ is the point where the $\Psi_{A \vee B}=\Psi^{e}$ curve intersects with the horizontal axis in Figure 4 (clearly, affected by model parameters). Suppose, by way of contradiction, that the governments coordinate the injection of free-flowing liquidity but force segmentation on the speculators. The amount of private-segmented liquidity is determined, implicitly, by a new function, $\Psi_{i}\left(\boldsymbol{\theta}_{M}^{*}\right)=\Psi^{e}$. By Corollary $1, \Psi_{A \vee B}\left(\boldsymbol{\theta}_{M}^{*}\right)>\Psi^{e}$; it follows that the graph of this new function lies to the left of the $\Psi_{A \vee B}=\Psi^{e}$ curve in Figure 4. Changes in public free-flowing liquidity shift the equilibrium along the curve. Since, by construction, country $i$ 's probability of crisis remains constant along the curve, Proposition 5's argument applies: segmentation trades off a severe crisis for an equal probability mild crisis and is therefore sub-optimal. Hence, the optimal policy is to inject sufficient free-flowing public liquidity to fully crowd out all private (segmented) liquidity. Clearly, total liquidity at this point (the new $\Psi_{i}\left(\boldsymbol{\theta}_{M}^{*}\right)=\Psi^{e}$ curve intersects with the horizontal axis) is equal to $\underline{\theta}_{T}^{*}$ and can thus be reached by allowing the free flow of private liquidity with no public liquidity injections. The combination of segmented public liquidity and free-flowing private liquidity therefore dominates. If both public and private liquidity are segmented, then the total liquidity supply can be increased by relaxing the flow constraint on private liquidity. By point (i) of Lemma 1, this is welfare improvement.

ii) Suppose that $\theta_{G}^{*} \geq \underline{\theta}_{T}^{*}$ and that condition (32) just holds: $\frac{\Delta}{\Gamma} \geq 2$ and $\frac{\theta_{G}^{*}}{\Theta}=\frac{3}{8} \frac{\frac{\Delta}{\Gamma}-2}{\frac{\Delta}{\Gamma}-\frac{3}{2}}$. By Proposition $6\left(\underline{\theta}_{T}^{*}, \underline{\theta}_{T}^{*}\right)$ welfare dominates $\left(0, \underline{\theta}_{T}^{*}\right)$, weakly (notice that the proof of Proposition 6 makes no use of the condition $\frac{\theta_{G}^{*}}{\Theta} \geq \sqrt{1-\Psi^{e}}$; hence, the statement holds regardless). In comparison, by part $i$ ) of Lemma 1 , an equilibrium where public segmented liquidity is $\theta_{G}^{*}$ and private liquidity is allowed to flow freely (a shift leftwards from the diagonal to the $\Psi_{A \vee B}=\Psi^{e}$ curve) welfare dominates $\left(\underline{\theta}_{T}^{*}, \underline{\theta}_{T}^{*}\right)$, strictly. By the continuity of the welfare manifold, it follows that segmentation is optimal under strictly weaker conditions than those of (32).

iii) The argument above implies that welfare is increasing in liquidity along the $\Psi_{A \vee B}=\Psi^{e}$ curve when $\frac{\Delta}{\Gamma} \geq 2$, including the case of equality. Consider the case where $\frac{\Delta}{\Gamma}$ is just below 2 and $\frac{\theta_{G}^{*}}{\Theta}$ just below $\sqrt{1-\Psi^{e}}$. By Proposition $6,\left(\sqrt{1-\Psi^{e}}, 0\right)$ dominates $\left(\sqrt{1-\Psi^{e}}, \sqrt{1-\Psi^{e}}\right)$. By continuity of the welfare manifold, coordinated governments should pool their resources and inject freely flowing liquidity, even at the "cost" of some loss of total liquidity.

\section{Proof of Proposition 9}

To prove part $i$ ), consider any symmetric candidate Nash equilibrium that has a positive amount of private liquidity supply. We analyze the best response of country, $A$. 
a) Suppose that country $B$ allows private liquidity to flow freely. If country $A$ also allows private liquidity to flow freely, then a regime of free flow obtains with a liquidity configuration somewhere on the $\Psi^{e}$ curve. If instead country $A$ segments private liquidity, its supply has to adjust until $\Psi_{A}=\Psi^{e}$, while private liquidity supply in $B$ adjusts until $\Psi_{A \vee B}=\Psi^{e}$. Since, by Corollary $1, \Psi_{A \vee B} \geq \Psi_{A}$, private liquidity supply in $A$ is fully crowded out, the liquidity configuration and welfare in $A$ remain unchanged.

b) Suppose that country $B$ segments private liquidity. If country $A$ also segments, then we obtain a liquidity configuration with segmented liquidity denoted by $\widehat{\theta}_{A, D}^{*}$, the precise value of which depends on the amount of public liquidity each government supplies, but that in any case generates a crisis probability $\Psi_{A}=\Psi^{e}$. If instead $A$ allows its private liquidity to flow freely, its supply adjusts to yield $\Psi_{A \vee B}=\Psi^{e}$. Hence, the crisis probability in $A$ falls or stays the same; but then, such a policy reduces the probability of crisis for realizations $\theta_{A}>\widehat{\theta}_{A, D}^{*}$ and increase the probability of crisis for realizations $\theta_{A}<\widehat{\theta}_{A, D}^{*}$. We already know that such a trade-off enhances welfare.

The proof of part ii) follows the same three cases as in Section 5.2. The argument for the $G=0$ is just a special case of the proof of part $i$ ). The main text elaborates. Moving to full crowding out, consider, first, the case where the constraint on $G$ binds. For any symmetric point $\boldsymbol{\theta}_{M}^{*} \in \mathcal{L}^{R}$, country $A$ has an incentive to increase segmentation unilaterally (i.e., increase $\theta_{A, D}^{*}$ ) as long as the partial derivative (28) is non-negative, which can be written as:

$$
\frac{\theta_{D}^{*}}{\Theta} \geq 2 \frac{\theta_{T}^{*}}{\Theta} \frac{\frac{\Delta}{\Gamma}-\frac{5}{2}}{\frac{\Delta}{\Gamma}-3}-\frac{\frac{\Delta}{\Gamma}-2}{\frac{\Delta}{\Gamma}-3} .
$$

If $\frac{\Delta}{\Gamma} \geq 2$, the condition (46) holds with strict inequality for any $\boldsymbol{\theta}_{M}^{*} \in \mathcal{L}^{R}$, so the Nash equilibrium exhibits full segmentation. By Proposition 6, social optima exhibit zero segmentation when $\frac{\Delta}{\Gamma} \geq 2$ and $\frac{\theta_{G}^{*}}{\Theta} \leq \frac{3}{8} \frac{\frac{\Delta}{\Gamma}-2}{\Gamma-\frac{3}{2}}$. Hence, equilibrium segmentation is strictly higher than the social optimum when $\frac{\theta_{G}^{*}}{\Theta}>\frac{3}{8} \frac{\frac{\Delta}{\Gamma}-2}{\frac{\Delta}{\Gamma}-\frac{3}{2}}$.

If $\frac{\Delta}{\Gamma}<2$, define an "ND" curve where condition (46) holds with equality so that country $A$ has a unilateral incentive to segment. For sufficiently large $\theta_{T}^{*}$, the ND curve lies within $\mathcal{L}^{R}$ : it intersects with the vertical axis between 0 and $-\frac{1}{2}$ and passes through the $(1,1)$ point in Figure 4 . It is easy to see that any point on the ND curve is a maximum in $\theta_{A, D}^{*}$ given $\theta_{T}^{*}$. Again, excess segmentation is established by the observation that, by Proposition 6 , for $\frac{\Delta}{\Gamma}<2$, the social optimum exhibits zero segmentation. If the $G$ constraint binds and intersects with the ND curve within $\mathcal{L}^{R}$, then the Nash equilibrium exhibits partial segmentation.

Next, consider any symmetric Nash equilibrium that has full crowding out and a non-binding $G$ constraint. To know when the $G$ constraint binds, we calculate country $A$ 's incentive to inject liquidity unilaterally. Since $\theta^{*}=\theta_{A}^{T}+\theta_{B}^{T}$, the incentive of an uncoordinated government to inject liquidity is given by adding up derivatives (29) and 
(31):

$$
\frac{\partial W_{A}}{\partial \theta_{A, T}^{*}}+\frac{\partial W_{A}}{\partial \theta^{*}}=\Gamma\left[\left(1-\Psi_{A \vee B}\right)\left(\frac{\Delta}{\Gamma}-1\right)+\left(\Psi_{A \vee B}-\Psi^{e}\right)\right]
$$

Note that the above expression is positive for $\Psi_{A \vee B}=\Psi^{e}$; hence, each government has an incentive to crowd out private liquidity. A sufficient condition for (47) to be positive at any $\Psi_{A \vee B}$ can be obtained by setting $\Psi_{A \vee B}=0$, which yields $\frac{\Delta}{\Gamma} \geq\left(1+\Psi^{e}\right)$. Hence, if $\frac{\Delta}{\Gamma} \geq\left(1+\Psi^{e}\right)$, then the Nash equilibrium must be at the corner where the $G$ constraint binds. If the social optimum also features a binding $G$ constraint, then the previous argument applies. If it does not, then we know that the social optimum features zero segmentation, so the Nash equilibrium can only have (weakly) too much segmentation. If $\frac{\Delta}{\Gamma}<\left(1+\Psi^{e}\right)$, then we know that the social optimum has zero segmentation, so again, the Nash equilibrium can only have (weakly) too much segmentation.

Finally, consider any symmetric candidate Nash equilibrium that has partial crowding out with public segmented liquidity and private free flowing liquidity, i.e., the Nash equilibrium lies on the $\Psi^{e}$ curve. The social incentive to segment along the $\Psi^{e}$ curve is given by differentiating the welfare function, using $\frac{\partial \theta_{A}^{*}}{\partial \theta_{D}^{*}}=\frac{\partial \theta_{B}^{*}}{\partial \theta_{D}^{*}}=1$ :

$$
\frac{d W_{A}}{d \theta_{D}^{*}}=\frac{\partial W_{A}}{\partial \theta_{A, D}^{*}}+\frac{\partial W_{A}}{\partial \theta_{B, D}^{*}}+\frac{\partial W_{A}}{\partial \theta_{A, T}^{*}}+\left.2 \frac{\partial \theta^{*}}{\partial \theta_{A, D}^{*}}\right|_{\Psi^{e}=\Psi_{A \vee B}} \frac{\partial W_{A}}{\partial \theta^{*}}
$$

The government of country $A$, when it is not coordinated with the government of country $B$, (i.e., $\frac{\partial \theta_{A}^{*}}{\partial \theta_{D}^{*}}=1, \frac{\partial \theta_{B}^{*}}{\partial \theta_{D}^{*}}=0$ ) increases segmentation as long as

$$
\frac{d W_{A}}{d \theta_{A, D}^{*}}=\frac{\partial W_{A}}{\partial \theta_{A, D}^{*}}+\frac{\partial W_{A}}{\partial \theta_{A, T}^{*}}+\left.\frac{\partial \theta^{*}}{\partial \theta_{A, D}^{*}}\right|_{\Psi^{e}=\Psi_{A \vee B}} \frac{\partial W_{A}}{\partial \theta^{*}}>0 .
$$

Since

$$
\frac{\partial W_{A}}{\partial \theta_{B, D}^{*}}+\frac{\partial \theta^{*}}{\partial \theta_{A, D}^{*}} \mid \frac{\partial W_{A}}{\partial \theta^{*}}<0
$$

it follows that $\frac{d W_{A}}{d \theta_{A, D}^{*}}>\frac{d W_{A}}{d \theta_{D}^{*}}$. 


\section{References}

[1] Acemoglu, D., A. Ozdaglar and A. Tahbaz-Salehi, 2015, "Systemic Risk and Stability in Financial Networks," American Economic Review, 105(2), 564-608.

[2] Acharya, V.V., 2003, "Is the International Convergence of Capital Adequacy Regulation Desirable?" Journal of Finance, 58(6), 2745-2781.

[3] Acharya, V.V., H.S. Shin and T. Yorulmazer, 2013, "A Theory of Arbitrage Capital," The Review of Corporate Finance Studies, 2, 62-97.

[4] Acharya, V., I. Drechsler and P. Schnabl, 2014, "A Pyrrhic Victory? Bank Bailouts and Sovereign Credit Risk", Journal of Finance, 69(6), 2689-2739.

[5] Allen, F. and D. Gale, 1994, "Limited Market Participation and Volatility of Asset Prices," American Economic Review, 84, 933-955.

[6] Allen, F. and D. Gale, 1998, "Optimal Financial Crises,", Journal of Finance, 53(4) $1245-1284$.

[7] Allen, F. and D. Gale, 2000, "Financial Contagion," Journal of Political Economy, 108(1), 1-33.

[8] Banal-Estañol, A., M. Ottaviani and A. Winton, 2013, "The Flip-Side of Financial Synergies: Coinsurance versus Risk Contamination," Review of Financial Studies, 26(12), 3142-3181.

[9] Bengui, J., 2014, "Macro-Prudential Policy Coordination," unpublished manuscript, University of Montreal.

[10] Bhattacharya, S. and D. Gale, 1987, "Preference Shocks, Liquidity and Central Bank Policy," in W. Barnett and K. Singleton (eds.) New approaches to monetary economics, Cambridge University Press.

[11] Brunnermeier, M. and Y. Sannikov, 2015, "International Credit Flows and Pecuniary Externalities," American Economic Journal: Macroeconomics, 7(1), 297-338.

[12] Brusco, S. and F. Castiglionesi, 2007, "Liquidity Coinsurance, Moral Hazard and Financial Contagion," Journal of Finance, 62(5), 2275-2302.

[13] Caballero, R. and A. Krishnamurthy, 2001, "International and Domestic Collateral Constraints in a Model of Emerging Market Crisis," Journal of Monetary Economics, 48(3), 513-548. 
[14] Caballero, R. and A. Krishnamurthy, 2003, "Excessive Dollar Debt: Financial Development and Underinsurance," Journal of Finance, 58(2), 867-894.

[15] Caballero, R. and A. Krishnamurthy, 2004, "Smoothing Sudden Stops," Journal of Economic Theory, 119(1), 104-127.

[16] Caballero, R. and A. Simsek, 2017, "A Model of Fickle Capital Flows and Retrenchment." NBER Working Paper No. 22751.

[17] Campbell, J. Y., S. Giglio and P. Pathak, 2011, "Forced Sales and House Prices," American Economic Review, 101, 2108-2131.

[18] Castiglionesi, F., F. Feriozzi and G. Lorenzoni, 2017, "Financial Integration and Liquidity Crises," forthcoming Management Science.

[19] Coval, J. and E. Stafford, 2007, "Asset Fire Sales (and Purchases) in Equity Markets," Journal of Financial Economics, 86(2), 479-512.

[20] Das, S. and R. Uppal, 2004, "Systematic Risk and International Portfolio Choice," Journal of Finance, 59(6), 2809-2834.

[21] Davila, E. and A. Korinek, 2018, "Pecuniary Externalities in Economies with Financial Frictions," Review of Economic Studies, 85(1), 352-395.

[22] Dell'Ariccia, G. and R. Marquez, 2006, "Competition among Regulators and Credit Market Integration," Journal of Financial Economics, 79(2), 401-430.

[23] Diamond, D. and P. Dybvig, 1983, "Bank Runs, Deposit Insurance and Liquidity," Journal of Political Economy, 91(3), 401-419.

[24] Duffie, D., 2010, "Asset Price Dynamics with Slow-Moving Capital," Journal of Finance, 65(4), 1237-1267.

[25] Ellul A. , C. Jotikasthira b, and C. T. Lundblad, 2011, "Regulatory Pressure and Fire Sales in the Corporate Bond Market," Journal of Financial Economics, 101(3), 596-620.

[26] Fernández, A., Rebucci, M. and M. Uribe, 2014, "Are Capital Controls Countercyclical?" Journal of Monetary Economics, 76, 1-14.

[27] Gorton, G., and L. Huang, 2004, "Liquidity, Efficiency, and Bank Bailouts," American Economic Review, 94(3), 455-483.

[28] Gromb, D. and D. Vayanos, 2002, "Equilibrium and Welfare in Markets with Financially Constrained Arbitrageurs," Journal of Financial Economics, 66, 361-407. 
[29] Gromb, D. and D. Vayanos, 2010, "Limits of Arbitrage: The State of the Theory," Annual Review of Financial Economics, 2, 251-275.

[30] Gromb, D. and D. Vayanos, 2010, "A Model of Financial Market Liquidity Based on Intermediary Capital," Journal of the European Economic Association, 8, 456-466.

[31] Gromb, Denis and Dimitri Vayanos, 2018, "The Dynamics of Financially Constrained Arbitrage," Journal of Finance, 73 (4). 1713-1750.

[32] Gertler, M., S. Gilchrist and F. Natalucci, 2007, "External Constraints on Monetary Policy and the Financial Accelerator," Journal of Money Credit and Banking, 39(23), 295-330.

[33] Haldane, A. G., 2009, "Rethinking the Financial Network," manuscript, Bank of England.

[34] Holmström, B. and J. Tirole, 1998, "Private and Public Supply of Liquidity," Journal of Political Economy, 106(1), 1-40.

[35] Holmström, B. and J. Tirole, 2011, Inside and Outside Liquidity, Boston: MIT Press.

[36] Jeanne, O. and A. Korinek, 2010, "Excessive Volatility in Capital Flows: A Pigouvian Taxation Approach," American Economic Review Papers and Proceedings, 100(2), 403-407.

[37] Jotikasthira, C., C. Lundblad and T. Ramadorai, 2012, "Asset Fire Sales and Purchases and the International Transmission of Funding Shocks," Journal of Finance, 67(6), 2015-2050.

[38] Kara, G., 2016, "Systemic Risk, International Regulation and the Limits of Coordination," Journal of International Economics, 99, 192-222.

[39] Kiyotaki, N. and J. H. Moore, 1997, "Credit Cycles," Journal of Political Economy, 105(2), 211-248.

[40] Korinek, A., 2010, "Regulating Capital Flows to Emerging Markets: An Externality View," unpublished manuscript, University of Maryland.

[41] Korinek, A., 2011, "Hot Money and Serial Financial Crisis," IMF Economic Review $59(2), 306-339$.

[42] Korinek, A., 2016, "Currency Wars or Efficient Spillovers? A General Theory of International Policy Cooperation," unpublished manuscript, Johns Hopkins University. 
[43] Krishnamurthy, A. and A. Vissing-Jorgensen, 2013, "The Ins and Outs of LSAPs," Proceedings - Economic Policy Symposium - Jackson Hole, Federal Reserve Bank of Kansas City..

[44] Krishnamurthy, A. and A. Vissing-Jorgensen, 2015, "The Impact of Treasury Supply on Financial Sector Lending and Stability," Journal of Financial Economics 118(3), 571-600.

[45] Kuong, J, 2015, "Self-fulfilling Fire Sales: Fragility of Collateralised Short-term Debt Markets", INSEAD WP, 2015/37/FIN.

[46] Kyle, A. and W. Xiong, 2001, "Contagion as a Wealth Effect," Journal of Finance 56(4), 1401-1440.

[47] Londono, J. M., 2016, "Bad Bad Contagion," Board of Governors of the Federal Reserve System, International Finance Discussion Papers, 1178.

[48] Longin, F. and B. Solnik, 2001, "Extreme correlation of international equity markets," Journal of Finance, 56(2), 649 - 676.

[49] Lorenzoni, G., 2008, "Inefficient Credit Booms," Review of Economic Studies, 75(3), 809-833.

[50] Lorenzoni, G., 2014, "International Financial Crises" in Handbook of International Economics, ed. by G. Gopinath, E. Helpman, and K. Rogoff, vol. 4. Elsevier.

[51] Mendoza, E.G., 2010, "Sudden Stops, Financial Crises and Leverage," American Economic Review, 100(5), 1941-1965.

[52] Mendoza, E.G. and V. Quadrini, 2010, "Financial Globalization, Financial Crises and Contagion," Journal of Monetary Economics, 57(1), 24-39.

[53] Mink, M. and J. de Haan, 2013, "Contagion during the Greek sovereign debt crisis," Journal of International Money and Finance, 34, 102-113.

[54] Morrison, A. and L. White, 2009, "Level Playing Fields in International Financial Regulation" Journal of Finance, 64(3), 1099-1142.

[55] Ostroy, J. D., P. Loungani, and D. Furceri, 2016, "Neoliberalism: Oversold?" Finance and Development, 38-41.

[56] Pavlova, A. and R. Rigobon, 2008, "The Role of Portfolio Constraints in the International Propagation of Shocks," Review of Economic Studies, 75(4), 1215-1256. 
[57] Pulvino, T., 1998, "Do Asset Fire Sales Exist? An Empirical Investigation of Commercial Aircraft Transactions," Journal of Finance 53(3), 939-978.

[58] Schnabl, P., 2012, "The International Transmission of Bank Liquidity Shocks: Evidence from an Emerging Market," Journal of Finance, 67(3), 897-932.

[59] Shleifer, A., and R. Vishny, 1992, "Liquidation Values and Debt Capacity: A Market Equilibrium Approach," Journal of Finance, 47(4), 1343-1366.

[60] Stiglitz, J.E., 1999, "Beggar-Thyself versus Beggar-Thy-Neighbor Policies: The Dangers of Intellectual Incoherence in Addressing the Global Financial Crisis," Southern Economic Journal, 66(1), 1-38.

[61] Stiglitz, J.E., 2010, "Risk and Global Economic Architecture: why Full Financial Integration may be Undesirable," American Economic Review, Papers \& Proceedings, 100(2), 388-392.

[62] Tirole, J., 2006, The Theory of Corporate Finance, Princeton: Princeton University Press.

[63] Veronesi, P. and L. Zingales, 2010, "Paulson's gift," Journal of Financial Economics, 97(3), 339-368.

[64] Wagner, W., 2010, "Diversification at Financial Institutions and Systemic Crises," Journal of Financial Intermediation, 19, 373-386. 